\title{
The ALADIN System and its canonical model configurations AROME CY41T1 and ALARO CY40T1
}

\author{
Piet Termonia ${ }^{1,2}$, Claude Fischer ${ }^{3}$, Eric Bazile $^{3}$, François Bouyssel $^{3}$, Radmila Brožková $^{4}$, Pierre Bénard $^{3}$, \\ Bogdan Bochenek ${ }^{5}$, Daan Degrauwe ${ }^{1,2}$, Mariá Derková ${ }^{6}$, Ryad El Khatib ${ }^{3}$, Rafiq Hamdi ${ }^{1}$, Ján Mašek ${ }^{4}$, \\ Patricia Pottier $^{3}$, Neva Pristov ${ }^{7}$, Yann Seity ${ }^{3}$, Petra Smolíková ${ }^{4}$, Oldřich Španiel ${ }^{6}$, Martina Tudor ${ }^{8}$, Yong Wang ${ }^{9}$, \\ Christoph Wittmann ${ }^{9}$, and Alain Joly ${ }^{3}$ \\ ${ }^{1}$ Royal Meteorological Institute, Brussels, Belgium \\ ${ }^{2}$ Department of Physics and Astronomy, Ghent university, Ghent, Belgium \\ ${ }^{3}$ CNRM/GMAP, Météo-France, Toulouse, France \\ ${ }^{4}$ Czech Hydrometeorological Institute, Prague, Czech Republic \\ ${ }^{5}$ Institute of Meteorology and Water Management - State Research Institute of Poland, Krakow, Poland \\ ${ }^{6}$ Slovak Hydrometeorological Institute, Bratislava, Slovakia \\ ${ }^{7}$ Slovenian Environment Agency, Ljubljana, Slovenia \\ ${ }^{8}$ Meteorological and Hydrological Service, Zagreb, Croatia \\ ${ }^{9}$ Zentralanstalt für Meteorologie und Geodynamik, Vienna, Austria
}

Correspondence: Piet Termonia (piet.termonia@ meteo.be)

Received: 29 April 2017 - Discussion started: 7 July 2017

Revised: 8 November 2017 - Accepted: 10 November 2017 - Published: 18 January 2018

\begin{abstract}
The ALADIN System is a numerical weather prediction (NWP) system developed by the international ALADIN consortium for operational weather forecasting and research purposes. It is based on a code that is shared with the global model IFS of the ECMWF and the ARPEGE model of Météo-France. Today, this system can be used to provide a multitude of high-resolution limited-area model (LAM) configurations. A few configurations are thoroughly validated and prepared to be used for the operational weather forecasting in the 16 partner institutes of this consortium. These configurations are called the ALADIN canonical model configurations (CMCs). There are currently three CMCs: the ALADIN baseline CMC, the AROME CMC and the ALARO CMC. Other configurations are possible for research, such as process studies and climate simulations.

The purpose of this paper is (i) to define the ALADIN System in relation to the global counterparts IFS and ARPEGE, (ii) to explain the notion of the CMCs, (iii) to document their most recent versions, and (iv) to illustrate the process of the validation and the porting of these configurations to the operational forecast suites of the partner institutes of the ALADIN consortium.
\end{abstract}

This paper is restricted to the forecast model only; data assimilation techniques and postprocessing techniques are part of the ALADIN System but they are not discussed here.

\section{Introduction}

The ALADIN System ${ }^{1}$ is the set of pre-processing, data assimilation, forecast model and post-processing-verification software codes shared and developed by the partners of the ALADIN consortium ${ }^{2}$ to be used for running a highresolution limited-area model (LAM) for producing the best possible operational numerical weather prediction (NWP) applications based on a configuration compatible with their available computing resources. The ALADIN consortium is a collaboration between the national (hydro)meteorological services (NHMSs) of 16 European and northern African

\footnotetext{
${ }^{1}$ The ALADIN acronym stands for Aire Limitee Adaptation Dynamique Développement International (International development for limited-area dynamical adaptation)

${ }^{2}$ See http://www.umr-cnrm.fr/aladin/.
} 
countries $^{3}$; see ALADIN international team (1997). This consortium was created in 1990.

The ALADIN consortium carries out an ambitious research program and has delivered a state-of-the-art NWP system that is used by its member states for their operational weather-forecasting applications. This is achieved by the following specific activities. The consortium performs research and development activities with the aim of maintaining the ALADIN System at scientific and technical state-of-the-art level within the NWP community. It carries out the necessary scientific and technical studies to define and maintain the ALADIN System and its canonical model configurations (CMCs). The consortium organizes the general maintenance of the ALADIN System with the aim to create new versions on a regular basis. It organizes coordination and networking activities in order to support the ALADIN consortium members in their ability to run the ALADIN canonical model configurations on the computing platforms of their national institutes. The consortium provides a platform for sharing scientific results, numerical codes, operational environments, related expertise and know-how, as necessary for all ALADIN consortium members to conduct operational and research activities with the same tools.

The collaboration follows the initial objectives of the consortium, as they were introduced by its founder JeanFrançois Geleyn:

a. to have or to gain with the help of other members the capability to define, build and run local versions of the ALADIN System, but also,

b. to build the capability to conceive, develop, test and ultimately integrate scientific ideas locally and finally in the new versions of the ALADIN System.

Both objectives lead to the benefit of all through the exchange of expertise and the improvements of the ALADIN System, and contributes to the steady progress of the discipline of NWP (Bauer et al., 2015). One consequence is that the consortium as a whole is responsible for the code as a whole. Therefore, creating a new version of the source code and its maintenance is a transversal activity within the consortium.

\footnotetext{
${ }^{3}$ Currently the partners of the ALADIN consortium are the (1) Office National de la Météorologie, Algeria; (2) Zentralanstalt für Meteorologie und Geodynamik, Austria; (3) Royal Meteorological Institute of Belgium, Belgium; (4) Bulgarian National Institute of Meteorology and Hydrology, Bulgaria, (5) Meteorological and Hydrological Service, Croatia; (6) Czech Hydrometeorological Institute, Czech Republic; (7) Météo-France, France; (8) Hungarian Meteorological Service, Hungary; (9) Direction de la Météorologie Nationale, Morocco; (10) Institute of Meteorology and Water Management - State Research Institute of Poland, Poland; (11) Instituto Português do Mar e da Atmosfera, Portugal; (12) National Meteorological Administration of Romania, Romania; (13) Slovak Hydrometeorological Institute, Slovakia; (14) Slovenian Environment Agency, Slovenia; (15) Institut National de la Météorologie de Tunisie; and (16) Turkish State Meteorological Service, Turkey.
}

While all partner services have the capacity to implement their operational versions of the ALADIN System by themselves, some activities are organized into more formally structured cooperations to develop applications that go beyond the deliverables of the ALADIN consortium.

The ALADIN consortium hosts the geographically localized regional cooperation for Limited-Area Modelling in Central Europe (RC LACE) consortium, with seven members: the national (hydro)meteorological services of Austria, Croatia, Czech, Hungary, Romania, Slovakia and Slovenia. It contributes a lot to the development of the ALADIN System. It made key contributions to the ALADIN nonhydrostatic dynamical core and the development of the physics parameterizations, in particular the ALARO CMC that will be described in Sect. 3.3. This consortium provides extra resources to exchange and to process meteorological data used for the operational data assimilation systems in the RC LACE partner countries. RC LACE develops and operates a panEuropean probabilistic system of limited-area ensemble forecasting (LAEF) based on the ALADIN System (Wang et al., 2011, 2014).

Since 2005, the ALADIN consortium also shares its code with the HIRLAM consortium ${ }^{4}$ through a cooperation agreement (Bengtsson et al., 2017).

The codes of the ALADIN System are common with the codes of the global Integrated Forecast system (IFS) of the ECMWF $^{5}$ and the global ARPEGE ${ }^{6}$ model of Météo-France (Courtier and Geleyn, 1988; Courtier et al., 1991). The common, shared codes of the ALADIN System are managed in a central repository maintained by Météo-France with the help of the partners of the ALADIN consortium. From this repository versions of the ALADIN System are assembled on a regular basis following the updates of the IFS cycles and the scientific improvements developed within the LAM community. This includes an assembling of the latest developments of ECMWF and Météo-France. The code evolution of the ALADIN System is thereby triggered by (i) updates with respect to IFS-ARPEGE versions, (ii) the implementation of novel scientific developments and (iii) specific code modernization (e.g., towards object-oriented code design) or optimization (for high-performance computing, HPC).

The aim of this link between the LAM and global models is threefold. First we can consider the configurations of the ALADIN System as limited-area configurations of the global model. Secondly, by sharing parts of the codes, the maintenance efforts can be reduced, and developments done in either global or limited-area models become mutually available. Lastly, as mentioned by Warner et al. (1997), keeping maximum consistency between the global model and the LAM model dynamics and physics can reduce the errors at

\footnotetext{
${ }^{4}$ HIgh-Resolution Limited-Area Model consortium.

${ }^{5}$ European Centre for Medium-Range Weather Forecasts.

${ }^{6}$ Action de Recherche Petite Echelle Grande Echelle.
} 
the lateral boundaries and can be beneficial for the lateralboundary coupling of the LAM.

A quasiinfinite number of choices can be made in the scientific physics and dynamics options of the configurations of the ALADIN System. This offers a high degree of freedom for the participating partners of the ALADIN consortium to configure their national NWP applications, and even to develop tailor-made applications to address specific requests from their end users. However, it should be stressed that not all combinations of the available dynamics and physics schemes lead to scientifically meaningful model configurations.

Historically the ALADIN model was created as the LAM version of ARPEGE (Radnóti et al., 1995). Since all of the ALADIN countries nowadays target their applications at resolutions within the so-called convection permitting scales, two physically consistent model configurations called $\mathrm{AROME}^{7}$ (Seity et al., 2011) and $\mathrm{ALARO}^{8}$ have been developed to address the need for applications at these resolutions. The current efforts to assemble, validate, document and maintain new versions of the ALADIN System are focused on these two "canonical" model configurations. However, in order to keep the close link with the global model ARPEGE, a LAM configuration that uses the ARPEGE physics is maintained. This configuration is still called the ALADIN model configuration. The new versions of these ALADIN model configurations are not collectively exported to operational NWP applications of the ALADIN partners anymore, but they undergo a minimal validation and can be used in scientific projects where a mesoscale model is needed.

This paper is organized as follows. In Sect. 2 the ALADIN System will be described. The purpose is to define the ALADIN System by indicating its specificities related to code architecture with respect to the global models ARPEGE and IFS, paying special attention to the validation process of the newest version of the ALADIN System. In Sect. 3 the notion of CMCs will be introduced in more detail. The scientific description of the recent CMCs will be presented. Section 4 will illustrate how the recent versions have been exported to the ALADIN partner countries. The paper will be concluded with a discussion and a short outlook in Sect. 5. The scope of this paper will be limited to the forecast model configurations. For instance, data assimilation is part of the ALADIN System codes but will not be described here, nor will any postprocessing methods.

\footnotetext{
${ }^{7}$ AROME stands for Application of Research to Operations at Mesoscale.

${ }^{8}$ ALARO stands for ALadin-AROme.
}

\section{Description of the ALADIN System}

\subsection{Generalities}

A version of the ALADIN System is a release of the ALADIN System. Some versions are distributed at regular times to the ALADIN partners for research and development, as well as for operational purposes. These versions are called export versions. A configuration of the ALADIN System is a subset of ALADIN Codes used by a consortium member for its own implementation. Canonical model configurations are configurations of the ALADIN System for which the ALADIN consortium organizes collective efforts for the scientific and technical validation according to the state of the art of the latest research and development. The consortium also organizes the coordination and networking activities in order to install and run these canonical configurations in the operational NWP suites of the ALADIN consortium members.

Today there are two CMCs in the full sense: the AROME model configuration and the ALARO model configuration. While the ALADIN configuration is not exported to the partners of the consortium anymore, it is considered as the baseline CMC to ensure the link with the global model ARPEGE.

Code updates are done about every 6 months: one common with IFS-ARPEGE, one common only to the ALADIN partners.

A new version build is planned about 1 year in advance, and this original kick-off decision is followed by an "upstream coordination" process with the intention to anticipate as much as possible any potential conflict between expected code commitments. This effort is considered strategic for the NWP system, due to its highly integrated nature, and it involves scientific experts along with system (programming) experts.

The practical understanding of the link between the global IFS-ARPEGE and the limited-area ALADIN code updates can be seen as a piece of genuine ARPEGE-ALADIN knowhow. Scientific developments performed first in one system might be of potential interest to the other system, which raises the question of how to thoroughly analyze the implementation steps for such a transfer of science. A few fundamental rules are followed.

- For spectral space codes, adaptations from spherical harmonics to bi-Fourier spectral decompositions (or vice versa) are routinely analyzed. This adaptation will usually result in specific new codes mimicking the call trees and the general structure of the original development (e.g., horizontal diffusion).

- For the grid-point computations involving geometry, adaptation from spherical definitions to plane projected settings, or vice versa, is done (e.g., horizontal interpolations). However, some general available data enable a common use of information in both codes, like the map 
factor of the projection or the direction of the geographical north.

- The handling of the poles is specific to the global code, and usually occurs as an optional code.

- The lateral boundaries are handled where necessary as optional code with respect to the global version. Likewise, the treatment of lateral boundary coupling is an optional code within the general time stepping of the whole system.

Section 2.2 provides more details about the code architecture of the ALADIN System within the IFS-ARPEGE framework. This rather unique duality between two geophysical numerical simulation codes has offered opportunities of cross-fertilization, like for instance the implementation of a nonhydrostatic dynamical kernel. The first code of nonhydrostatic dynamics appeared in the limited-area system, and was a few years later adapted to the global version. Note that adapting to the global code was not a mandatory decision for the full IFS-ARPEGE and ALADIN systems to be maintained in regular conditions. The decision eventually was taken when the scientific opportunity for this transfer became obvious. However, the first versions of the semi-Lagrangian advection code were developed in IFS-ARPEGE and then converted into the limited-area version. This conversion actually happened quickly, as it opened the floor for significantly longer time steps in the hydrostatic LAM configurations that were operated in the 1990s.

The practical steps of the initial build of a new ALADIN version release are mostly taking place at Météo-France: merge of code contributions and early validation process. Progressively, as the early versions become technically stable, some remote installation and further validation can take place, until the new release is declared. This process does not comprise preoperational local implementations in which the meteorological quality of a new release is evaluated, beyond the technical tests.

The technical validation is done in several steps, some of which are ignored if found to be unnecessary:

1. a benchmark of base tests - adiabatic model versions, change of model grid geometry versions, tangentlinear/adjoint model run tests, and specific forecast tests including physics packages among which those used for defining the CMCs;

2. comparison with the previous reference version, aiming to trace back changes that disrupt bit reproducibility, or to put it differently, verifying that bit reproducibility is broken for understood reasons;

3. computation of statistical scores such as bias and rootmean-square errors (RMSEs) with respect to observations or reference analyses;
4. specific model output diagnostics used in research mode like averages of model tendencies;

5. one-dimensional model tests to assess profiles of fields and their tendencies;

6. specific data assimilation test periods are run (the time period is chosen in order to match with a recent context for the throughput of observations).

This process is meant to bring the embedded implementations of the LAM configurations of the ALADIN System in phase with the cycles of the global IFS and the ARPEGE models and is called "phasing". The cycle numbers of the ALADIN versions are the same as the corresponding cycles of IFS and ARPEGE. The outcome of the build and validation process is a new version of the ALADIN System labeled in the Météo-France central source code repository. Mature versions of the ALADIN System are packages in so-called "export versions" for installation in the ALADIN partner centers.

\subsection{The scientific and technical specificities of the code architecture of the ALADIN System}

The definition of the ALADIN System is rooted in the options of the shared code to configure the LAM model configurations. This section describes the architecture of the code to outline what is common with the global model and what differentiates the LAM configurations from the global model.

One of the main concerns in the developments of these codes $^{9}$ is the special care taken to be able to run the model configurations with long time steps or, to put it nondimensionally, with large Courant numbers. Most of the choices in the development of the numerical treatments of the dynamics and the physics parameterizations are made from that point of view. As far as is known today, from recent intercomparisons (see, e.g., Michalakes et al., 2015) this key feature, combined with hybrid (MPI-OpenMP) parallelization capabilities makes IFS-ARPEGE-ALADIN models the most efficient or cheapest ones to run, in each of their categories, in terms of "time to solution".

The code of the ALADIN System is shared with the code of the IFS of ECMWF and the ARPEGE model of Météo-France. The current operational versions use a spectral dynamical core with a two-time level semiimplicit semiLagrangian (SISL) scheme (Ritchie et al., 1995; Robert et al., 1972; Simmons et al., 1978; Temperton et al., 2001). The use of a spectral transform method naturally implies that there is no horizontal staggering of the variables in the grid-point calculations part. To solve the semiimplicit problem, the dynamic equations are reduced to a single Helmholz equation

\footnotetext{
${ }^{9}$ Historically the code had to run in time-critical applications on a large variety of available computing platforms across the different partners of the ALADIN consortium - hence the specific care for numerical efficiency through the use of large time steps.
} 
Table 1. Schematic overview of the time-step algorithm of the configurations of the ALADIN System and the choices that differentiate them with respect to the global ARPEGE model.

\begin{tabular}{|c|c|c|}
\hline & Step & Options (LAM vs. global) \\
\hline 1. & Horizontal derivatives (vorticity, divergence and pressure-temperature gradients) & \\
\hline 2. & Inverse spectral transform: spectral to grid point & $\begin{array}{l}\text { bi-FFT }^{-1} \\
\text { Legendre, FFT }\end{array}$ \\
\hline 3. & Computation of the physics contributions & $\begin{array}{l}\text { AROME physics } \\
\text { ALADIN/ALARO physics }\end{array}$ \\
\hline 4. & Calculation of the tendencies of the prognostic variables of the model state & INTFLEX \\
\hline 5. & $\begin{array}{l}\text { Computation of the explicit grid-point dynamics and } \\
\text { adding it to the total tendencies of the prognostic variables }\end{array}$ & $\begin{array}{l}\text { IFS-ARPEGE-ALADIN hydrostatic } \\
\text { ALADIN-NH }\end{array}$ \\
\hline 6. & $\begin{array}{l}\text { Computation of the semi-Lagrangian departure points and } \\
\text { Interpolation of the tendencies to these points }\end{array}$ & SLHD \\
\hline 7. & Addition of the interpolated tendencies to the model state & \\
\hline 8. & Lateral boundary coupling & bi-periodic LBC conditions \\
\hline 9. & direct spectral transforms & $\begin{array}{l}\text { bi-FFT } \\
\text { Legendre, FFT }\end{array}$ \\
\hline 10. & solving the semiimplicit Helmholtz equation & $\begin{array}{l}\text { IFS-ARPEGE-ALADIN hydrostatic } \\
\text { ALADIN NH }\end{array}$ \\
\hline
\end{tabular}

in the horizontal divergence. In the equations of the dynamics the $u$ and $v$ components of the wind fields are recast in terms of absolute momentum. As such the Coriolis term, as well as the curvature terms, do not appear on the right-hand side and, as a result, do not enter the linearized semiimplicit formulation. Indeed, the approach taken to solve the SI problem is remarkably efficient insofar as the problem is horizontally separable: then, the spectral method enables an elegant, direct purely algebraic solution. This efficiency is lost whenever parameters depending on the horizontal coordinates are kept in the linear problem. Actually, one such parameter, the map factor, does enter the SI problem, but its horizontal dependency is handled in a semianalytical way, leading to a weakly nondiagonal problem in spectral space, therefore enabling most of the advantages of the spectral solving method to be kept.

The time-step computations are organized in such a way that the same dynamics formulations can be used for both limited-area and global geometries. The time-step algorithm is schematically outlined in Table 1 in a simplified manner.

Note that this algorithm is not the same for IFS as far as the physical parameterizations calculations are concerned. In the IFS, the physics is performed on variables at different times depending on the physical process, whereas in the ARPEGE model and the ALADIN System it is performed entirely on the $t-\delta t$ state variable before calling the explicit part of the dynamics; see Termonia and Hamdi (2007).

Three features differentiate the ALADIN System configurations from its global counter part:

1. the choice of the horizontal bi-Fourier spectral transform instead of the spherical spectral transforms (steps 1, 2, 9 in Table 1) and a formulation of the
Helmholtz equation in term of the proper operators and map factors (step 10),

2. the lateral-boundary conditions (step 8 in Table 1), and

3. the physics packages which are adapted in step 3 in Table 1 , for an application at the high resolutions targeting the convection-permitting scales, as shown in Fig. 2.

\subsubsection{The ALADIN-NH nonhydrostatic dynamical core}

The code can be run with a nonhydrostatic dynamical core that solves the fully compressible Euler equations (Bubnová et al., 1995). This dynamical core is referred to as ALADIN$\mathrm{NH}$ and may be used in both AROME CMC and ALARO CMC typically for horizontal grid-point distance shorter than approximately $3 \mathrm{~km}$. This is a rough limit when the size of smallest circulation structures resolved in horizontal becomes comparable to their largest vertical size and so the nonhydrostatic effects become progressively important starting from there.

The vertical coordinate system uses a mass-based hybrid pressure terrain-following coordinate $\eta$ (Simmons and Burridge, 1981; Laprise, 1992). The vertical discretization is based on finite differences (Simmons and Burridge, 1981) or finite elements. For the latter the implementation of B-splines of either linear or cubic order (Untch and Hortal, 2004) can be used in the hydrostatic case only, while in the nonhydrostatic case B-splines of general order are introduced according to Vivoda and Smolíková (2013). Unlike the hydrostatic case, in the ALADIN-NH dynamical core not only the integral operators but also the vertical derivatives need to be discretized since they appear in the set of basic equations. 
Moreover, the basic constraints being satisfied in the continuous case with the finite-difference vertical discretization are not fulfilled by the finite-element vertical discretization. It follows that the elimination of all prognostic variables but one is not possible when solving the Helmholtz equation, and an iterative procedure is being applied in this case.

There are two additional prognostic variables compared to the hydrostatic model core: the nonhydrostatic pressure departure from the hydrostatic pressure and a specific expression of the vertical-divergence variable, denoted as $d$.

This choice ensures satisfactory stability properties of the semiimplicit scheme (Bénard et al., 2004, 2005). However, in the semi-Lagrangian advection scheme, in the case of a flow over steep slopes, the accuracy of the calculation may be reduced depending on the choice of the bottom boundary condition for $d$. The solution proposed by Smith (2002) is to use the vertical wind $w$ instead of vertical divergence in the explicit part of the semiimplicit calculations. This allows the free-slip lower boundary condition to be introduced in its most natural form, without the need for any extra assumptions. These simpler calculations then lead to an enhanced accuracy in the vicinity of steep slopes. Vertical staggering of prognostic variables is a necessary consequence of this approach, resulting in the calculation of two sets of semiLagrangian trajectories, one at full model levels for most of the prognostic variables and a second one at the intermediate levels for the vertical velocities. Furthermore, a transformation from $w$ to $d$ and vice versa needs to be performed at the beginning and at the end of the explicit computations. Recently, more conservative semi-Lagrangian horizontal weights were proposed which take into account the deformation of air parcels along each direction in the COMAD scheme (Malardel and Ricard, 2015). This scheme allows for the use of more conservative horizontal interpolation weights for the variables temperature, wind, specific moisture, surface pressure, pressure departure and vertical divergence.

The nonhydrostatic equation set can be solved using a separable linear noniterative semiimplicit problem. However, the parameter domain of stability is reduced with respect to the hydrostatic case. One way of improving it is to use two distinct temperatures in the scheme, instead of a single one. Roughly, one characterizes gravity waves, the other acoustic waves. To go further, Bénard (2003) proposes seeing the semiimplicit scheme as a highly linearized single iteration approximation to the tangent-linear iterative fix-point search of the more exact solution. From this analysis, he derives a more stable but iterative scheme called the iterative centered implicit scheme. A number of dynamical nonlinear terms are recomputed at each iteration, with optional precision (and cost) levels, and the SI solved again with recomputed righthand terms. This scheme can alternatively be viewed as belonging to the predictor-corrector family.

The dynamical core (both hydrostatic and nonhydrostatic) includes a linear numerical horizontal diffusion based on a power of the Laplace operator as proposed by
Jakimow et al. (1992). The operator is included in the solver of the Helmholtz equation in the spectral part of the computations in step 10 in Table 1 and is thus solved implicitly. For the iterative centered implicit time scheme, the spectral horizontal diffusion is applied at each iteration step, whilst physical tendencies and semi-Lagrangian trajectories may not be recomputed and could be kept from the predictor step.

\subsubsection{SLHD: a semi-Lagrangian horizontal diffusion scheme}

The code also allows the use of a nonlinear semi-Lagrangian horizontal diffusion (SLHD) scheme, computed under step 6 of the time-step algorithm in Table 1. The original version of the scheme was developed and implemented by Váña et al. (2008). Later its conservative properties were improved by using a carefully constructed class of semi-Lagrangian interpolators, exploiting the fact that accuracy and damping properties of an interpolator are not strictly tied. On a 4-point stencil in one dimension it is possible to construct a class of second-order accurate interpolators with broadly varying damping, and with spectral selectivity equivalent to the fourth-order diffusion. An additional control of spectral response is obtained by using an optional Laplacian smoother. Nonlinearity of the SLHD scheme is achieved via a modulation of the diffusion strength by the horizontal deformation rate of the flow. Due to its grid-point character, the scheme also enables the application of diffusion on quantities that are not transformed to spectral space, such as specific humidity, cloud condensates or the turbulent kinetic energy (TKE).

\subsubsection{Digital-filtering initialization (DFI) and scale-selective DFI (SSDFI)}

The shared code also allows a digital-filtering initialization (DFI) on a model state to be performed (Lynch, 1990). In operational applications an optimal version is used (Lynch et al., 1997) based on a Dolph-Chebyshev filter (Lynch, 1997). Termonia (2008) observed that such temporal filters may filter out fast-moving signals on the small scales and implemented a scale-selective digital-filtering initialization (SSDFI) in the shared ARPEGE-ALADIN code.

Most of the above-described features are embedded in the common code with the global ARPEGE model.

\subsubsection{Implementation of the Davies lateral-boundary coupling}

The structure of the geographical domain of the LAM configurations is based on the idea of Haugen and Machenhauer (1993). It has three zones, as shown in Fig. 1, consisting of a physical central zone (C), an intermediate zone (I) where the lateral-boundary conditions are imposed by a relaxation, and a so-called extension zone (E) where artificial periodic extensions of the fields are inserted before performing the direct fast Fourier transforms. The double periodicity implies 


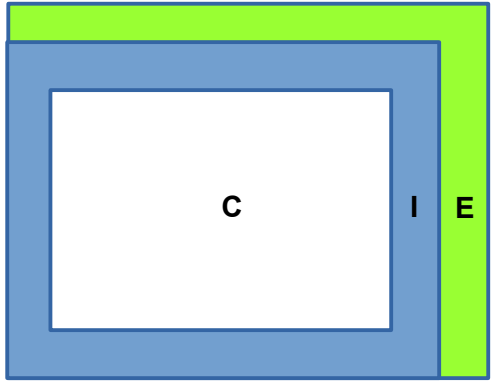

Figure 1. The domain of the LAM model is composed of three zones: a physical central zone (C), an intermediate zone (I) where the lateral-boundary conditions are imposed by a relaxation, and the extension zone (E) where artificial periodic extensions of the fields are inserted.

that the geometry of the spectral LAM is essentially a torus as opposed to a sphere for the global model configurations. In operational applications the $\mathrm{C}+\mathrm{I}$ domain is most commonly mapped onto the sphere by means of a conformal-Lambert projection. The other two conformal projections are also possible, namely the polar stereographic and the Mercator projections.

The LAM configurations of the ALADIN System use the Davies (1976) relaxation scheme in the I zone in Fig. 1, which nudges the fields from the fields of the host model to the guest model. Instead of using the proposed nudging coefficients by Davies (1983), in the ALADIN System this is done using a parameterized function:

$\alpha(z)=1-(p+1) z^{p}+p z^{p+1},$,

where $z$ is the normalized distance from the boundary of the $\mathrm{C}$ zone to the border of the I zone. The shape of the relaxation curve $\alpha$ is fixed by tuning the variable $p$ (the current configurations use a value of $p=2.16$ for wind and temperature, and $p=5.52$ for water vapor and hydrometeors). The width of the I zone is typically 8 grid points, but this number is increased in the implementations with high resolutions (e.g., for the $1.3 \mathrm{~km}$ resolution setup of Météo-France 16 grid points are used). For the size of the E zone 12 grid points are taken.

In the ALADIN System the lateral-boundary conditions are imposed in step 8 in Table 1 just before the spectral transforms. This is done by relaxing the result of the explicit part of the dynamics (computed in step 5 in Table 1) to the fields of the host model after they have been subjected to the operator of the semiimplicit scheme as proposed by Radnóti (1995). Symbolically this is written as follows:

$\boldsymbol{X}^{\mathrm{cpl}}=\alpha \boldsymbol{X}_{\mathrm{G}}+(1-\alpha)\left(1-\frac{\Delta t}{2} \mathcal{L}\right) \boldsymbol{X}_{\mathrm{H}}$,

where $\boldsymbol{X}_{\mathrm{G}}$ is the updated tendency of the LAM model state after step $7, \boldsymbol{X}_{\mathrm{H}}$ is the field of the host model, $\mathcal{L}$ is the linear operator of the semiimplicit scheme and $\alpha$ is taken as in
Eq. (1). The result of Eq. (2), $\boldsymbol{X}^{\mathrm{cpl}}$ is then transformed to spectral space and becomes the input to the Helmholtz solver in step 10. The fields are made periodic in the extension zone by spline functions.

\subsubsection{Implementation of Boyd's scheme and extensions thereof}

The new biperiodization and LBC scheme proposed by Boyd (2005) has been implemented in the ALADIN System by Termonia et al. (2012). They introduced some other options to adapt it to the semi-Lagrangian scheme and to make the scheme more flexible. For instance, the code can be run with a disjoint split between the relaxation in the I zone and the biperiodic windowing in the $\mathrm{E}$ zone of Fig. 1, which improves upon the original proposal of Boyd (2005) where the relaxation and the biperiodic windowing overlap. It has been shown that such a configuration with a truncation of the semi-Lagrangian trajectories at the edge of the $\mathrm{C}+\mathrm{I}$ zone, gives better results than the Davies scheme (Degrauwe et al., 2012).

\subsubsection{Interpolations of initial and coupling data in space and time}

In practice the configurations of the ALADIN System are coupled to the IFS or to the ARPEGE model. To this end the dynamical fields are spatially interpolated to the LAM domain. The periodic extensions are inserted in the E zone at this stage. To run the system with Boyd's scheme, one needs the information of the fields of the host model outside the $\mathrm{C}$ and the I zone; see Termonia et al. (2012). The results are stored in files. These files usually contain the spectral coefficients of the dynamical fields. Such files are created at Météo-France or ECMWF and transferred to the ALADIN partners in a timely manner. They are computed with the resolution corresponding to the average horizontal resolution of the driving model, not the target one, to save bandwidth and transfer time. These files are short-handedly called the telecom files.

The interpolation software also allows the interpolation of the fields of a LAM configuration to a LAM subdomain with possibly a new resolution. The telecom files are created at regular times with $1 \mathrm{~h}, 3 \mathrm{~h}$ or $6 \mathrm{~h}$ time intervals. These files are read during a forecast run of the guest model and interpolated in time to get the fields at each time step. Note that time interpolations of the bi-periodic fields yields bi-periodic fields. In practice the time interpolation is carried out by a linear interpolation or a quadratic interpolation (Tudor and Termonia, 2010). Termonia (2004) found that a temporal interpolation of $3 \mathrm{~h}$ coupling updates may, in rare cases of a fast-moving storm entering the domain through the boundaries, result in errors of up to about $10 \mathrm{hPa}$ in the mean-sea-level pressure fields (Termonia et al., 2009). Termonia et al. (2011) proposed to use an error-detection 
procedure based on a recursive digital filtering procedure within the global model and to apply a restart in such cases. This procedure is used operationally in the forecast suite of the Royal Meteorological Institute (RMI). Alternative ways for detecting the errors from the fields available in the telecom files from IFS have been explored (Tudor, 2015).

\subsubsection{The coupling of the physics schemes to the dynamical core by the flexible physics-dynamics interface INTFLEX}

The scientific content of the physics schemes that are called under step 3 in Table 1 for ALADIN, ALARO and AROME will be described in Sect. 3 .

The coupling of the physics to the dynamics (step 4 in Table 1) is based on a flux-conservative formulation developed by Catry et al. (2007). A flexible version of this physics-dynamics interface, called INTFLEX, has been recently implemented and validated in the common code by Degrauwe et al. (2016) that facilitates the implementation of new species and processes. The use of INTFLEX for the AROME configuration has improved the life-cycle dynamics of the cold pool mechanism in deep convective systems. The INTFLEX code functions as an interface routine to plug in the different physics packages in the time-step algorithm. It is common to the ARPEGE model and to the configurations of the ALADIN System.

\subsubsection{Parallelism}

For the efficiency of the LAM configurations on modern parallel computing architectures, the same strategies as for the global IFS-ARPEGE models are employed, with limited needs of adaptation. Mostly thanks to ECMWF and the integration concept, this code is characterized by a rather rare fully parameterized hybrid parallelization (MPI-OpenMP) capability. This means that the code can use various mixes of distributed memory parallel tasks and shared memory parallel threads. On the current dominant interconnected multi-CPU boards, the LAM configurations primarily use the same cache-blocking mechanism for cache-based computers $^{10}$ (Zwieflhofer et al., 2003; Hamrud et al., 2012). This comes along with two-dimensional message passing distributions (MPI), both in spectral space and in grid-point space. On top of this cache-blocking slicing the LAM configurations can further use a parallelism by OPEN-MP threads.

Recently, the performance on large computing domains has been significantly improved by introducing an input-

\footnotetext{
${ }^{10}$ These are the so-called NPROMA blocks, named after the dimensioning NPROMA variable. This variable was initially designed to optimize the vectorization length on vector machines. The NPROMA blocking was developed first for vector shared memory machines. Then the code was adapted for vector distributed memory machines by introducing MPI. Since then OpenMP has been progressively implemented.
}

output (I/O) server developed by Météo-France. It enables to resume the time integration itself, while the writing to disk is performed in parallel. Reading may also be distributed. Dual parallelization makes it possible to use multicore boards. Dual parallelization combined with parallel I/O together with a much reduced number of time steps to reach a given forecast range makes these codes extremely efficient, even though the transpositions required by the use of spectral transforms are not ideal from a scalability viewpoint.

The main three particularities of the LAM parallelism with respect to the global model configurations concern the following:

1. the handling of the coupling data in grid-point space, for which a specific message passing distribution and parallelism has been developed;

2. the handling of the limited-area aspects in grid-point space (unlike in the global model, the semi-Lagrangian trajectories have to be constrained to the physical area $\mathrm{C}+\mathrm{I}$ and possibly a margin of the extension zone in the case of the Boyd solution mentioned above. Also, the semi-Lagrangian trajectories are computed on a plane, which requires, among other things, to construct the socalled halo for the MPI implementation in a different way);

3. In spectral space, the distributed Fourier-transform code is shared with the global model in the zonal direction (while in the other direction a second distributed Fourier transform code replaces the distributed Legendre transforms).

\section{The canonical model configurations}

The three physics packages ALADIN, AROME and ALARO can be called under step 3 of the time-step organization in Table 1. Their target resolutions are illustrated in Fig. 2. The AROME CMC and the ALARO CMC are respectively based on the cycles CY41T1 and CY40T1 and both are described in Sect. 3.2 and 3.3.

\subsection{The ALADIN baseline CMC}

The current ALADIN baseline CMC calls the ARPEGE physics that is used at Météo-France between summer 2013 and spring 2017. Here we limit ourselves to a brief description of this version.

Its radiation scheme is based for the long-wave on the so-called Rapid Radiative Transfer Model (RRTM) scheme (Mlawer et al., 1997; Iacono et al., 2008) and for the shortwave the six-band Fouquart-Morcrette scheme (Fouquart and Bonnel, 1980; Morcrette, 1993). The boundary layer parameterization is based on the prognostic equation of the turbulent kinetic energy (TKE) (Cuxart et al., 2000) that is also used in the AROME CMC but is associated with the shallow 
Table 2. The ALADIN CMC.

\begin{tabular}{|c|c|c|}
\hline Parameterization and dynamics & Scheme & References \\
\hline Dynamics & hydrostatic ARPEGE-ALADIN & Temperton et al. (2001), Radnóti et al. (1995) \\
\hline Radiation & RRTMG_LW, SW6 & $\begin{array}{l}\text { Mlawer et al. (1997), Iacono et al. (2008), } \\
\text { Fouquart and Bonnel (1980) }\end{array}$ \\
\hline Turbulence & CBR & Cuxart et al. (2000), Bougeault and Lacarrere (1989) \\
\hline Microphysics & & Lopez (2002), Bouteloup et al. (2005) \\
\hline Shallow convection & KFB & Bechtold et al. (2001), Bazile et al. (2011) \\
\hline Deep convection & & Bougeault (1985) \\
\hline Clouds & & Smith (1990) \\
\hline Sedimentation scheme & & Bouteloup et al. (2011) \\
\hline Orographic gravity wave drag & & Catry et al. (2008) \\
\hline Surface scheme & SURFEX & Masson et al. (2013) \\
\hline LBC scheme & Davies scheme & Davies (1976), Radnóti (1995), Termonia et al. (2012) \\
\hline
\end{tabular}

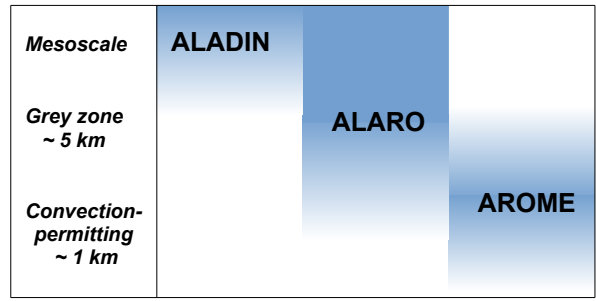

Figure 2. The different LAM configurations of the ALADIN System and their target resolutions.

convection scheme (KFB) based on a CAPE closure (Bechtold et al., 2001); both schemes are linked to the thermal production of TKE computed by the KFB scheme and by a modification of the original mixing length from Bougeault and Lacarrere (1989) by the shallow cloud from KFB (Bazile et al., 2011). The deep convection is represented by an updated version of the mass-flux scheme based on a moisture convergence closure (Bougeault, 1985). Alternatively, deep convection can now be represented using the PCMT scheme (prognostic condensates microphysics and transport) (Piriou et al., 2007; Guérémy, 2011). This scheme is already operational in the ARPEGE ensemble prediction system, and will soon be in ARPEGE. The cloud microphysics has four prognostic variables (cloud water and ice and liquid and solid precipitation) for the resolved precipitation (Lopez, 2002; Bouteloup et al., 2005), and the probability distribution function for the statistical cloud scheme comes from Smith (1990). A parameterization of subgrid orographic effects (Catry et al., 2008) represents gravity wave drag, wave deposition, wave trapping, form drag and lift effects. For the continental surface the SURFEX software (Masson et al., 2003) is used with the options used in the AROME model configuration, as will be described below and in Sect. 3.2. The chosen physics schemes of the ALADIN CMC are summarized in Table 2.

\subsection{The AROME CMC}

The AROME canonical model configuration has been developed to run in the convection-permitting resolutions starting from $2.5 \mathrm{~km}$ resolution. It is a nonhydrostatic convectivescale limited-area model setup described by Seity et al. (2011) and Brousseau et al. (2016). Its physical parameterizations come mostly from the Méso-NH research model (Lafore et al., 1998) whereas the dynamical core is the nonhydrostatic ALADIN core described in Sect. 2.2.1. It is run with a light, single-iteration predictor-corrector step which allows the use of long time steps $(50 \mathrm{~s}$ at $1.3 \mathrm{~km}$ horizontal resolution for instance). The recent versions of the AROME configurations ${ }^{11}$ use the COMAD scheme for the semi-Lagrangian advection as is also described in Sect. 2.2.1.

The AROME configuration uses a turbulence scheme based on a prognostic equation of TKE, a mass flux shallow convection scheme, a one-moment microphysics prognostic scheme, a detailed surface scheme and a radiation scheme described below.

The representation of the turbulence is based on a prognostic TKE equation (Cuxart et al., 2000) combined with a diagnostic mixing length (Bougeault and Lacarrere, 1989). The conservative variables defined for this TKE scheme are liquid potential temperature and the total water vapor (addition of water vapor and cloud-water-specific contents). The turbulence scheme used in AROME differs from the one used in ALADIN mainly on the vertical discretization of TKE defined on full levels versus half-levels respectively. Both schemes have been compared in several one-dimensional cases and the results are very similar. There is an ongoing work to share exactly the same code.

A mass flux scheme (Pergaud et al., 2009) based on the eddy diffusivity mass flux (EDMF) approach (Soares et al., 2004) is used as parameterization of dry thermals and shallow cumuli. This scheme uses the same conservative vari-

\footnotetext{
${ }^{11}$ COMAD is active in the ALADIN System code since CY40T1 and in particular in the current cycle CY41T1 described here.
} 
ables as the turbulence scheme. In the boundary layer, the formulations depend on the buoyancy and on the vertical speed of the updraft, whereas in clouds, they are computed using a Kain-Fritsch buoyancy sorting (Kain and Fritsch, 1990). Some improvements have been introduced in the latest version of the scheme (more consistent treatment of solid phase in the updraft, algorithmic corrections).

A statistical cloud scheme is used in AROME (Bechtold et al., 1995; Bougeault, 1982) based on the computation of the variance of the departure to a local saturation inside the grid box diagnosed by the turbulence scheme. The cloud fraction and the cloud condensate content are given by a combination of a Gaussian and a skewed exponential PDF. The cloud profiles of the shallow convection are combined with the cloud parameters resulting from the statistical adjustment. Apart from turbulence and convection, there can be other sources of variance like gravity waves, in particular with stable conditions when turbulent and convective contributions are too weak to produce clouds. In order to represent these extra sources of variance, a variance term proportional to the saturation total water-specific humidity is added to the term computed by the turbulence scheme (de Rooy et al., 2010). In this way, in particular conditions (weak turbulence), the cloud scheme's characteristics are those of a relative-humidity scheme where cloud cover is simply a function of the relative humidity.

AROME uses a one-moment microphysics scheme (Pinty and Jabouille, 1998; Lascaux et al., 2006), named ICE3, with five prognostic variables of water condensates (cloud droplets, rain, ice crystals, snow and graupel). ICE3 is a three-class ice parameterization coupled to a Kessler's scheme for the warm processes. Hail is also implemented but not activated in the current version of AROME. The diameter spectrum of each water species is assumed to follow a generalized Gamma distribution. Power-law relationships are used to link the mass and the terminal fall speed velocity to the particle diameters. More than 25 processes are parameterized in a sequential way inside this scheme. A PDFbased sedimentation scheme is used for the numerical efficiency of the microphysics computation with relatively long time steps, as described in Bouteloup et al. (2011). In order to investigate the aerosol-cloud interactions, a two-moment mixed microphysical scheme (Vié et al., 2016) has been developed in Meso-NH and implemented in AROME (used in research mode, not yet activated in the operational suite).

AROME uses the surface modeling platform SURFEX (Masson et al., 2013). Each model grid box is split into four tiles: land, towns, sea and inland waters (lakes and rivers). The interactions between soil, biosphere, and atmosphere (ISBA) parameterization (Noilhan and Planton, 1989) with three vertical layers inside the ground is activated over land tiles. The town energy budget (TEB) scheme used for urban tiles (Masson, 2000) simulates urban microclimate features, such as urban heat islands. Sea tiles use a bulk iterative parameterization, named ECUME (exchange coeffi- cients from unified multicampaigns estimates) (Belamari and Pirani, 2007). It is a bulk iterative parameterization developed in order to obtain an optimized parameterization covering a wide range of atmospheric and oceanic conditions. Concerning inland waters, the classic Charnock (Charnock, 1955) formulation is used. Physiographic data are initialized with the ECOCLIMAP database (Masson et al., 2003) at $1 \mathrm{~km}$ resolution. The orography is computed from the GMTED2010 database at $250 \mathrm{~m}$ resolution (Carabajal et al., 2011). The FAO HWSD database at $1 \mathrm{~km}$ resolution is used for the fraction of clay and sand in the soil. The HIRLAM parameterization of orography-radiation interactions (Senkova et al., 2007) has been adapted and implemented in the SURFEX version. Orographic shadowing and slope parameterizations are used operationally to modify solar direct radiative fluxes. One main effect of including shadowing and slope effects is that the clear-sky sunshine duration is drastically modified in mountainous areas, with values changed from almost constant to highly varying (sunshine duration can for instance locally reach about zero on grid points with all-day shadow conditions in the French Alps).

AROME uses the same radiation scheme as the ALADINbaseline CMC. It is a simplified version of the European Centre for Medium-Range Weather Forecasts (ECMWF) radiation parameterizations. The shortwave radiation scheme (Fouquart and Bonnel, 1980) uses six spectral bands. Cloud optical properties are derived from Morcrette and Fouquart (1986) for liquid clouds and Ebert and Curry (1992) for ice clouds. Cloud cover is computed using a maximum-random overlap assumption. The effective radius of liquid cloud particles is diagnosed from cloud liquid water using the Martin et al. (1994) formulation. Cloud nuclei concentrations are assumed to be constant, with one value over land and another over the ocean. The effective radius of ice clouds particles is diagnosed from temperature using a revision of the $\mathrm{Ou}$ and Liou (1995) formulation. Long-wave radiation is computed by the RRTM code (Mlawer et al., 1997) using climatological distributions of ozone and aerosols. Ozone monthly profiles are given by analytical functions that have been fitted to the UK Universities Global Atmospheric Modelling Programme (UGAMP) climatology (Li and Shine, 1995) with three coefficients (Bouteloup and Toth, 2003). The distributions of organic, sulfate, dust-like and black carbon, plus uniformly distributed stratospheric background aerosols, are extracted from the Tegen climatology (Tegen et al., 1997). Because of computational constraints, in all AROME configurations (2.5 or 1.3 horizontal resolution) full radiation computations are performed once every $15 \mathrm{~min}$. For intermediate time steps, only solar azimuth angle varies.

The choices of the physics parameterizations of the AROME CMC are summarized in Table 3. With these settings of the AROME model dynamics and physics parameterizations, the AROME CMC is capable of capturing in occasionally impressive manner the location, timing and strength of intense small-scale weather patterns. Figure 3 is an illus- 
Table 3. The AROME CMC.

\begin{tabular}{|c|c|c|}
\hline Parameterization and dynamics & Scheme & References \\
\hline Dynamics & nonhydrostatic ALADIN & Bénard et al. (2010) \\
\hline Radiation & RRTMG_LW, SW6 & $\begin{array}{l}\text { Iacono et al. (2008), Mlawer et al. (1997), Fouquart and Bonnel (1980), } \\
\text { Morcrette (2001) }\end{array}$ \\
\hline Turbulence & CBR & Cuxart et al. (2000), Bougeault and Lacarrere (1989) \\
\hline Microphysics & ICE3 & Pinty and Jabouille (1998) \\
\hline Shallow convection & PMMC09 & Pergaud et al. (2009) \\
\hline Deep convection & - & \\
\hline Clouds & & Bechtold et al. (1995), Pergaud et al. (2009) \\
\hline Sedimentation scheme & & Bouteloup et al. (2011) \\
\hline Surface scheme & SURFEX & Masson et al. (2013) \\
\hline LBC scheme & Davies scheme & Davies (1976), Radnóti (1995), Termonia et al. (2012) \\
\hline
\end{tabular}

tration of a case of onset of severe convective precipitation over the French Riviera and the city of Cannes (3 October 2015). For this case, where large-scale and local effects are most likely both important for triggering the onset of the heavy precipitation (more than $100 \mathrm{~mm}$ in $3 \mathrm{~h}$ ), the model forecast, started $15 \mathrm{~h}$ before the validation time, already provided a very realistic description of the event.

Météo-France is the main center for the developments of the AROME CMC. The French operational implementation, called AROME-France, is the flagship regional forecast system covering mainland France and the neighboring regions. The AROME configuration has been first implemented in operations on 18 December 2008 in Météo-France. The current version has a resolution of $1.3 \mathrm{~km}$ and 90 vertical levels. The ensemble version and a number of overseas and commercial applications are based on a $2.5 \mathrm{~km}$ resolution, using the same 90 levels, reaching very close to the surface.

The AROME configuration is also, by design, a vehicle for the developments of data assimilation of high-resolution observational data (Fischer et al., 2005; Wattrelot et al., 2014; Brousseau et al., 2016). Thus the AROME-France initial conditions at model resolution are provided by an hourly 3D-Var cycle for the atmospheric fields and a $3 \mathrm{~h}$ optimal interpolation for the surface fields.

The performance of the AROME CMC at Météo-France is regularly statistically assessed with respect to observations or specific analysis products. The verification encompasses WMO types of scores and more focused statistical evaluations as illustrated in Fig. 4. Figure $4 a$ and $b$ show the frequency bias and the Brier skill score for a range of precipitation thresholds for the whole year of 2016, respectively. In these two evaluations, the ability of AROME to outperform a rule of persistence of the forecast is assessed. The reference values, considered as the "truth", are specific analyses of accumulated precipitation obtained from the French ANTILOPE analysis product, which combines radar and rain gauge data (Laurantin, 2008). Ideally, both the frequency bias and the Brier skill score should be 1 for any threshold (for any event). While obviously the operational AROME sys-
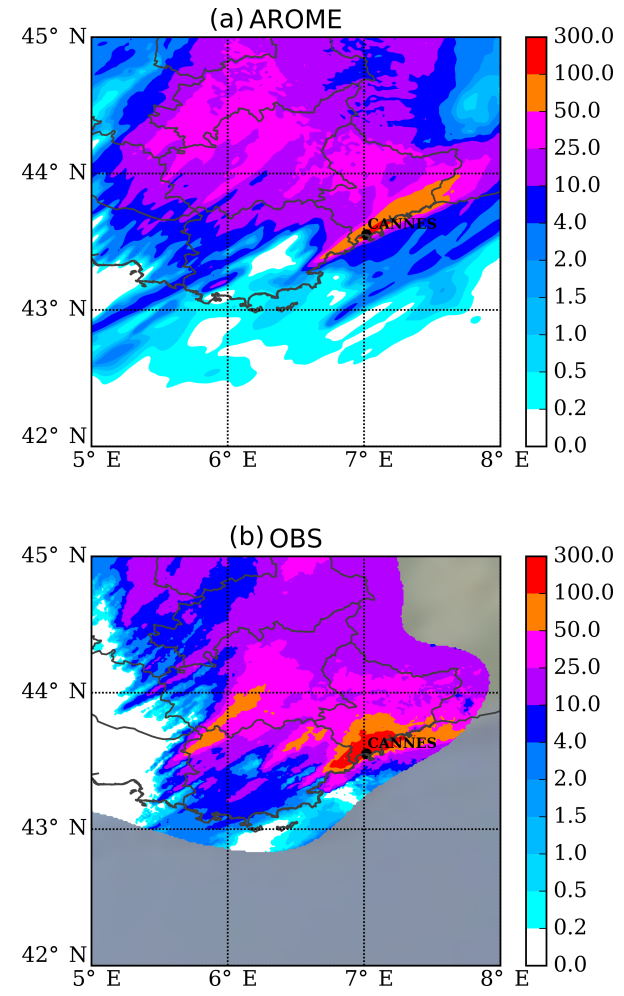

Figure 3. Maps of $3 \mathrm{~h}$ cumulated precipitations $(\mathrm{mm})$ between 18:00 and 21:00 UTC over the southeast of France, for the case of 3 October 2015. (a) AROME-France forecast starting at 03:00 UTC, (b) Antilope $3 \mathrm{~h}$ precipitation analysis taken as proxy to the observation (Laurantin, 2008).

tem would not exactly reach the theoretical "perfect model" values, the departure from the perfect model results is better appreciated when compared to the results of another modeling system. At Météo-France, AROME results can readily be compared to those of the global ARPEGE system, which are also depicted in Fig. 4. The comparison illustrates that the AROME system significantly improves the bias of fore- 

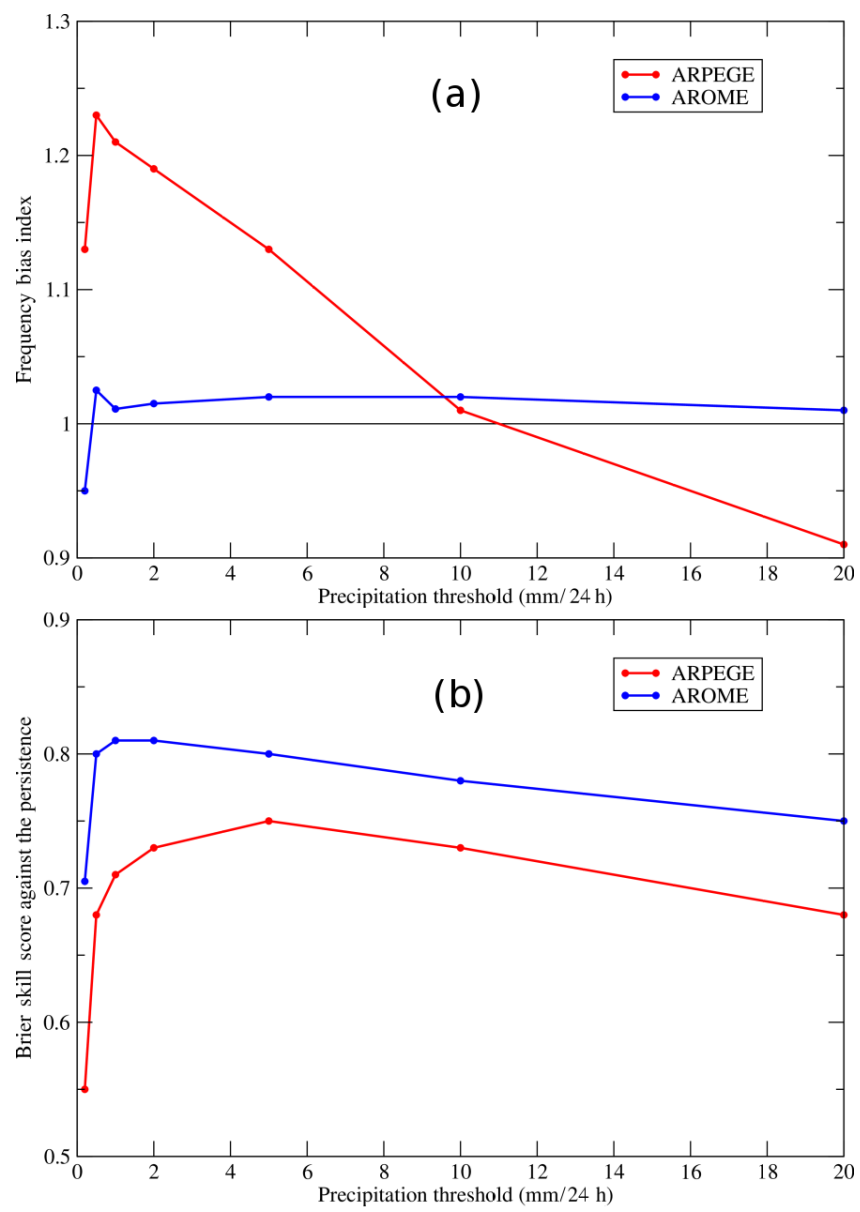

Figure 4. Frequency bias index (a) and Brier skill score (b) against the persistence for a fixed neighborhood of about $50 \mathrm{~km}$ (Amodei et al., 2015) computed for $24 \mathrm{~h}$ accumulated precipitation over France as a function of classes of precipitation $(0.2,0.5,1,2,5$, $10,20 \mathrm{~mm}$ per $24 \mathrm{~h}$ ). Forecasts are provided by the AROME-France and ARPEGE operational NWP systems at Météo-France, the start time is 00:00 UTC, the forecast lead time is $30 \mathrm{~h}$, and the scores are computed for the year 2016. The ANTILOPE precipitation analysis (Laurantin, 2008), combining radar and gauge data, is taken as reference. All data were interpolated on a regular grid of $2.5 \mathrm{~km}$.

cast precipitation amounts as well as the Brier skill score for almost all thresholds, with respect to ARPEGE.

\subsection{The ALARO CMC}

The ALARO physics is implemented in the ALADIN System under the same calling routines as those for the ALADIN configurations in step 3 of Table 1.

The aim of the ALARO configurations of the ALADIN System is to provide a setup that can also be used in intermediate resolutions between the mesoscale and the convectionpermitting scales; see Fig. 2. The partners of the ALADIN consortium are running their applications on a variety of computing platforms with different available computing re- sources. This approach allowed those who can not afford to run the model at kilometric resolutions to increase the resolutions in a progressive way. De Troch et al. (2013) demonstrated the multiscale behavior of ALARO in the statistics of extreme precipitation in long climate runs.

The basis for this is the application of a multiscale parameterization concept. For moist deep convection, the Modular Multiscale Microphysics and Transport scheme (3MT) has been developed to overcome problems when convection gets partly resolved at the so-called gray-zone model resolutions. The ALARO configuration is built upon this physics parameterizations concept relying on the governing equations for the moist physics, cast in a flux-form (Catry et al., 2007), a corner stone for the clean interface between the model physics and dynamics.

From the code point of view, new versions of the schemes are developed by taking utmost care of the ascending compatibility with the former versions. This allows easier validations, progressive upgrades and tailoring of the scientific complexity of the local applications. The coding and the numerical solutions strive for economical use of computing resources and are developed to allow for the long time steps allowed by the dynamical core. New schemes are also designed to be modular at the level of processes rather than at the level of full schemes.

The 3MT scheme is based on a mass-flux formulation and is designed to be used at the so-called convection-permitting model resolutions, i.e., for model grid lengths going from about $10 \mathrm{~km}$ down to a few hundred meters. It is described in detail in Gerard et al. (2009). Here we recall the main assumptions that were used for the development of this scheme.

The 3MT scheme does not rely on any assumption that convective cells cover a negligible fraction of the grid-box area, since this is not valid when increasing the resolution. Diagnostic relationships are therefore replaced by a time integration of the deep convection equations. In particular, the prognostic equations are solved for the updraft velocity, the downdraft velocity and also for the mesh area fractions occupied by the updraft and the downdraft, respectively. The quasiequilibrium hypothesis commonly used in deep convection parameterizations is abandoned. Instead 3MT uses a prognostic closure, relying on the cloud-base updraft area evolution.

The older parameterization concept of scale separation, common to coarser-resolution models, is not retained. Instead, the suggestion of Piriou et al. (2007) to separate convective transport and microphysics terms was further elaborated in 3MT. The net condensation in the updrafts is directly estimated and passed to the microphysics scheme for a joint treatment with the cloud scheme condensation input. This together with the abovementioned prognostic formulation of the convective transport allows the escape of an otherwise quite delicate parameterization of the detrainment and the pseudo-subsidence terms. It can be seen from a detailed analysis of the equations (not done here) that the 3MT scheme 
formulation mimics the behavior of cloud-system-resolving models (CSRMs) in the cloud-resolving limit.

In coarser-resolution models, the condensation is usually treated by two separate parameterization schemes, the socalled cloud scheme for nonconvective (stratiform) clouds and the moist deep convection scheme. In contrast CSRMs rely on convective drafts that are fully resolved by the model dynamics and all the condensation is computed by the cloud scheme. To avoid these two limits, inapplicable within the convection-permitting scales, and also to allow for a smooth transition to the CSRM limit, the scheme steps are organized in a cascade. The cloud scheme condensation, derived from Xu and Randall (1996) and alternatively from Smith (1990), is computed first. It provides a modified thermodynamic state as input for the convective updraft computations to prevent a double condensation counting. The cloud-scheme and updraft condensation fluxes are then joined later and treated by a single call to the microphysics. This sequence is made possible by the abovementioned microphysics-transport separation. The resulting precipitation flux gives an input to the downdraft computation, treating transport and complementary evaporation of precipitation.

In the convection-permitting scales it is still necessary to account for the subgrid-scale features of the unresolved updrafts condensation and the resulting precipitation. In the 3MT scheme this is done at the thermodynamic adjustment step of the cloud scheme and in the microphysics. Suspended water droplets and ice crystals of the convective cloud portion of the grid box are protected against their reevaporation during the adjustment in the next time step. The microphysics computations take into account the geometry of clouds and precipitation vertical overlaps to get a more realistic cloud and precipitation scene within the grid box. The geometry scheme is the exponential-random scheme from Hogan and Illingworth (2000) with a seasonal variation inspired by Oreopoulos et al. (2012). Seeking parameterization consistency, the same vertical overlap scheme is used in the radiation scheme, described below. It should be noted that the overlap computations are general and fully valid even if there is no contribution from the subgrid updraft condensation. It also should be noted that precipitation could activate downdrafts without an a priori existence of updrafts.

Microphysics is therefore at the central position of the 3MT scheme in the organization of the ALARO CMC physics time step, for which a single call ensures a smooth and implicit transition between grid scale and the unresolved origin of precipitation. It works with six species - dry air, water vapor, suspended liquid and ice cloud water, rain, and snow. The thermodynamics obeys the governing equations of Catry et al. (2007) and it is equally applicable if eventual subtypes of solid precipitations like graupel and/or hail are introduced. By construction modularity is kept at the level of processes allowing for their progressive sophistication within the same frame, e.g., vertical overlap geometry and sedimentation. At their current version the pa- rameterizations of auto-conversion, collection, evaporation and freezing-melting are inspired by the work of Lopez (2002). The Wegener-Bergeron-Findeisen effect is treated as an auto-conversion following Hage (1995). The sedimentation of precipitations is computed statistically (Geleyn et al., 2008) with a variable fall speed of species.

In order to enhance consistency and unification of parameterizations, the strategy employed in ALARO is to use prognostic, memory-keeping schemes (Yano et al., 2016). As an example, in 3MT the convective mesh updraft and downdraft fractions have a prognostic formulation. Similarly, prognostic equations for updraft and downdraft vertical velocities based on the proposal by Gerard and Geleyn (2005) are introduced. The result is a CSRM-type set of equations without any explicit presence of detrainment terms. In other words, it interacts with the dynamics in the same manner as a CSRMtype model does.

One can argue that bulk parameterizations should converge in their behavior to the behavior of CSRMs in the cloud-resolving limiting resolutions. If the prognostic equations of the mesh fraction and the updraft-vertical velocity scale properly, then the equations should converge to the equations of a CSRM. This yields a mechanism to control this convergence and to formulate a scale-aware parameterization of deep convection.

The 3MT scheme was introduced mid-2008 in a predecessor of the ALARO configuration operations in the application in CHMI (Prague), allowing the resolution to increase to $4.7 \mathrm{~km}$, i.e., to enter the gray zone of moist deep convection. It was the world first application of the prognostic microphysics-transport separation concept in NWP. The multiscale properties of 3MT are demonstrated in Fig. 5, comparing precipitation patterns obtained with a classical steady plume type of moist deep convection scheme (Gerard and Geleyn, 2005) and 3MT at resolutions of 9 and $4.7 \mathrm{~km}$.

Recently, good results were found up to a resolution of $1 \mathrm{~km}$, when running the so-called gray-zone experiment cold air outbreak case (Field et al., 2017). Further enhancements are currently entering the common library: unsaturated downdraft and complementary subgrid-scale updraft formulations, which are expected to still improve the convergence of the parameterized moist deep convection to the resolved case (Gerard, 2015; De Meutter et al., 2015).

In the same spirit of separating the precipitating and nonprecipitating processes, shallow convection is part of the turbulence scheme TOUCANS (Third Order moments Unified Condensation And N-dependent Solver). This parameterization of turbulence takes the advantage of recent theoretical proposals, such as the revisited Mellor-Yamada system (Mellor, 1973; Mellor and Yamada, 1974, 1982; Cheng et al., 2002; Canuto et al., 2008), quasinormal-scale elimination (QNSE) theory (Sukoriansky et al., 2005), and energy and flux budget (EFB) theory (Zilitinkevich et al., 2013), following Ďurán et al. (2014). All of these theories abandon the 


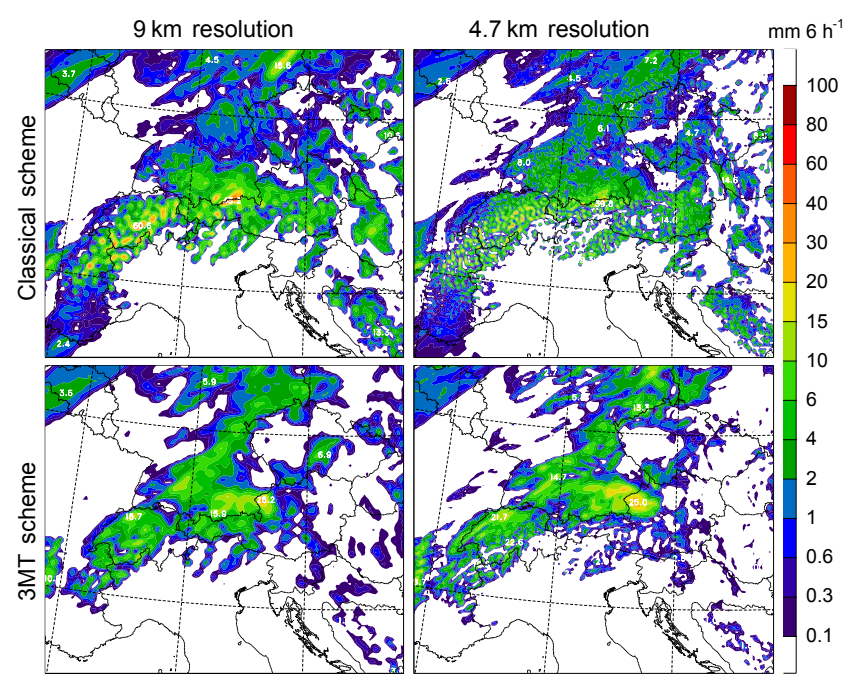

Figure 5. Precipitation accumulated between the +12 and $+18 \mathrm{~h}$ forecast times starting on 21 June 2006 at 00:00 UTC given by the ALARO application in CHMI (Prague). The chosen case is a summer convection in central Europe.

concept of the critical Richardson number, beyond which turbulence would cease.

Since TOUCANS can emulate Mellor-Yamada type of stability dependency functions, valid for all stability conditions, as well as the QNSE and EFB systems; all these models of turbulence are coded. The ALARO CMC retains the so-called model II of Durán et al. (2014). In addition, the scheme has been extended to a nonlocal third order moment (TOM) terms (based on Canuto et al., 2007) and to a prognostic equation for moist total turbulent energy (TTE). This concept makes it possible to better treat the anisotropy of the flow and to account for countergradient heat fluxes.

The closure-discretization method is a "stability dependent adjustment for turbulent energy modeling" (Ďurán et al., 2014), meaning that prognostic equations for turbulent energies are used, but the turbulent fluxes in the source terms are computed by assuming equilibrium of turbulent energies. This assumption ensures realizibility of the scheme for all conditions (Ďurán et al., 2014). Because of the specific computation of source terms, the scheme could be classified as between level 2.0 and level 2.5 of the Mellor-Yamada turbulence closure model if only TKE is used as turbulence prognostic variable. By adding a second prognostic energy, the scheme effectively has a prognostic equation for heat variance, and could be classified between level 2.0 and level 3.0 in the Mellor-Yamada system. There are four closure values of the so-called free parameters, which are set according to the model of turbulence, and the turbulence (exchange coefficient) length scale. A conversion between the length scale and a concrete choice of the mixing length is applied. Prandtl-type mixing length (Geleyn et al., 2006) or TKE- based mixing length (Bougeault and Lacarrere, 1989) formulations can be used.

The introduction of moisture in the turbulence scheme, i.e., accounting for phase changes, leading to density changes and latent heat release, is based on the recent formulation of moist Brunt-Väisälä Frequency (BVF) (Marquet and Geleyn, 2013). The nonprecipitating (shallow) convection scheme of TOUCANS also makes use of this moist BVF, abandoning the older concept of the modified Richardson number in the presence of condensed water. As for the other ALARO schemes, TOUCANS obeys the governing equations, principles of modularity, memory through prognostic schemes, and ascending compatibility. Indeed, the older turbulence scheme (Louis, 1979) can be emulated by the TOUCANS framework.

As an enhancement of the Louis scheme a pseudoprognostic TKE treatment (Geleyn et al., 2006) was introduced in a predecessor of the ALARO configuration and was put in operation in early 2007. The ALARO CMC with the so-called turbulence model II choice in TOUCANS has been operationally implemented in early 2015 together with the new radiation scheme ACRANEB2 described below.

Parameterization of radiative transfer is one of the most expensive computations in NWP models, therefore a compromise between the cost and accuracy is required. In the case of ALARO the choice is to keep the cloud-radiation interaction at full spatial and temporal model resolutions, to account for the fast development and the increased variability of cloudiness that manifest themselves with the increasing resolutions of the model applications. To achieve this, the ALARO CMC builds on a broadband approach with single shortwave and single long-wave spectral intervals, where almost linear scalability of long-wave computations (including scattering) with respect to the number of vertical levels is obtained via the so-called net exchanged rate (NER) decomposition with bracketing.

Currently, the ALARO CMC offers two radiative transfer schemes. The original scheme, denoted as ACRANEB, is best described in chap. 9.3 of Coiffier (2011), with some components originating from Ritter and Geleyn (1992). Thanks to cheap gaseous transmission calculations based on the Padé-corrected Malkmus band model, and to statistically fitted bracketing weights, full radiative transfer computations at every model grid point and time step are affordable. Somewhat less accurate gaseous transmissions are counterweighted by the full interaction of clouds and gasses with radiation, ensuring realistic model feedbacks.

The second version, called ACRANEB2 (Mašek et al., 2016; Geleyn et al., 2017), was developed with the goal to increase the accuracy of gaseous transmissions, cloud optical properties and the NER technique, while still keeping the full cloud-radiation interaction. Several spectrally unresolved effects had to be parameterized. Cloud optical properties were refitted against modern datasets and the shortwave cloud optical saturation was revised. The computational ef- 
Table 4. The ALARO CMC.

\begin{tabular}{|c|c|c|}
\hline Parameterization and dynamics & Scheme & References \\
\hline Dynamics for $\mathrm{d} x>4 \mathrm{~km}$ & hydrostatic ARPEGE-ALADIN & Temperton et al. (2001), Radnóti et al. (1995) \\
\hline Dynamics for $\mathrm{d} x<4 \mathrm{~km}$ & nonhydrostatic ALADIN & Bénard et al. (2010) \\
\hline Radiation & ACRANEB2 & Mašek et al. (2016), Geleyn et al. (2017) \\
\hline Turbulence & TOUCANS & Ďurán et al. (2014), Marquet and Geleyn (2013) \\
\hline Microphysics & Lopez & Lopez (2002) \\
\hline Shallow convection & TOUCANS & Ďurán et al. (2014), Marquet and Geleyn (2013) \\
\hline Deep convection & $3 \mathrm{MT}$ & Gerard et al. (2009) \\
\hline Sedimentation scheme & & Geleyn et al. (2008) \\
\hline Orographic gravity wave drag & & Catry et al. (2008) \\
\hline Surface scheme & ISBA & Noilhan and Planton (1989) \\
\hline LBC scheme & Davies scheme & Davies (1976), Radnóti (1995), Termonia et al. (2012) \\
\hline
\end{tabular}

ficiency of the scheme is ensured by selective intermittency, where rapidly varying cloud optical properties are updated at every model time step, while slowly varying gaseous transmissions only once per hour. In a shortwave band, gaseous transmissions at every model time step are updated to the actual sun elevation. In a long-wave band, a two-level intermittency is applied, where the full set of gaseous transmissions needed for the self-calibration of the bracketing weights is calculated only every $3 \mathrm{~h}$. From the cost versus accuracy point of view, ACRANEB2 is one of the most balanced radiation schemes used in NWP, which makes it fully competitive to the mainstream strategy based on infrequent calls of the very accurate but expensive correlated $k$-distribution method. The key point making the selective intermittency affordable in terms of memory requirements is the use of the broadband approach. This is because the storage needed for gaseous transmissions is linearly increasing with the number of spectral bands.

The ALARO CMC, in contrast to the AROME one, contains the gravity wave drag parameterization (Catry et al., 2008) needed when running at coarser resolutions. The resolution limit from which this parameterization can be dropped is considered to be roughly $5 \mathrm{~km}$, yet the operational experience with ALARO run at $4.7 \mathrm{~km}$ still shows its benefit. This scheme is shared with the global model ARPEGE although it uses a different tuning in ALARO; in other words it is shared with the ALADIN baseline CMC.

The choices of the physics parameterizations of the ALARO CMC are summarized in Table 4.

The reference versions of the ALARO are maintained in CHMI. Scientifically sound versions are committed during the phasings to the central repository in Météo-France. The ALARO CMCs are created once their model configurations have successfully passed the technical validations mentioned in Sect. 2.1.

Some physics parameterizations can be shared between the two configurations. For instance, the ALARO CMC calls the ISBA surface scheme directly, but it is possible to call the SURFEX scheme from the ALARO configurations. The per- formance of such an inclusion has been tested by Hamdi et al. (2014) in cycle CY36 of the ALADIN System. Additionally the interfaces to the radiation scheme have been cleaned and the ACRANEB2 radiation scheme (Mašek et al., 2016; Geleyn et al., 2017) of the ALARO configurations can be called from the AROME physics package, relying on the common physics-dynamics interface INTFLEX.

\section{Operational implementation of the ALADIN CMCs in the partner countries}

By using the canonical configurations the ALADIN partners can be sure that they are running a configuration with physically consistent choices. The installation and upgrade of the ALADIN System is performed by the partners individually, thanks to the high level of expertise gathered in each NHMS during the past course of the ALADIN project. Dedicated and coordinated efforts are made to support the installations of the newest cycle at partners' NHMS in order bring to them at a state-of-the-art level, allowing the partners to implement the newest research and development achievements. The support also comprises the collection and redistribution of information about known problems and their fixes.

\subsection{Current status of the implementations}

The ALADIN System is run operationally at all 16 partners' NHMSs on the domains depicted in Fig. 6. The model configurations are coupled to the global models ARPEGE or IFS. The lateral-boundary coupling data is transferred in a timely manner from Météo-France for the ARPEGE model and from ECMWF for the IFS data. Every partner adapts the ALADIN System parameters (domain size, horizontal and vertical resolution, integration length, driving model) according to his needs and according to his telecommunications and computing capacities. The different operational versions are named by the partners, referring to the three configurations ALADIN, AROME or ALARO. Table 5 summarizes the AL- 

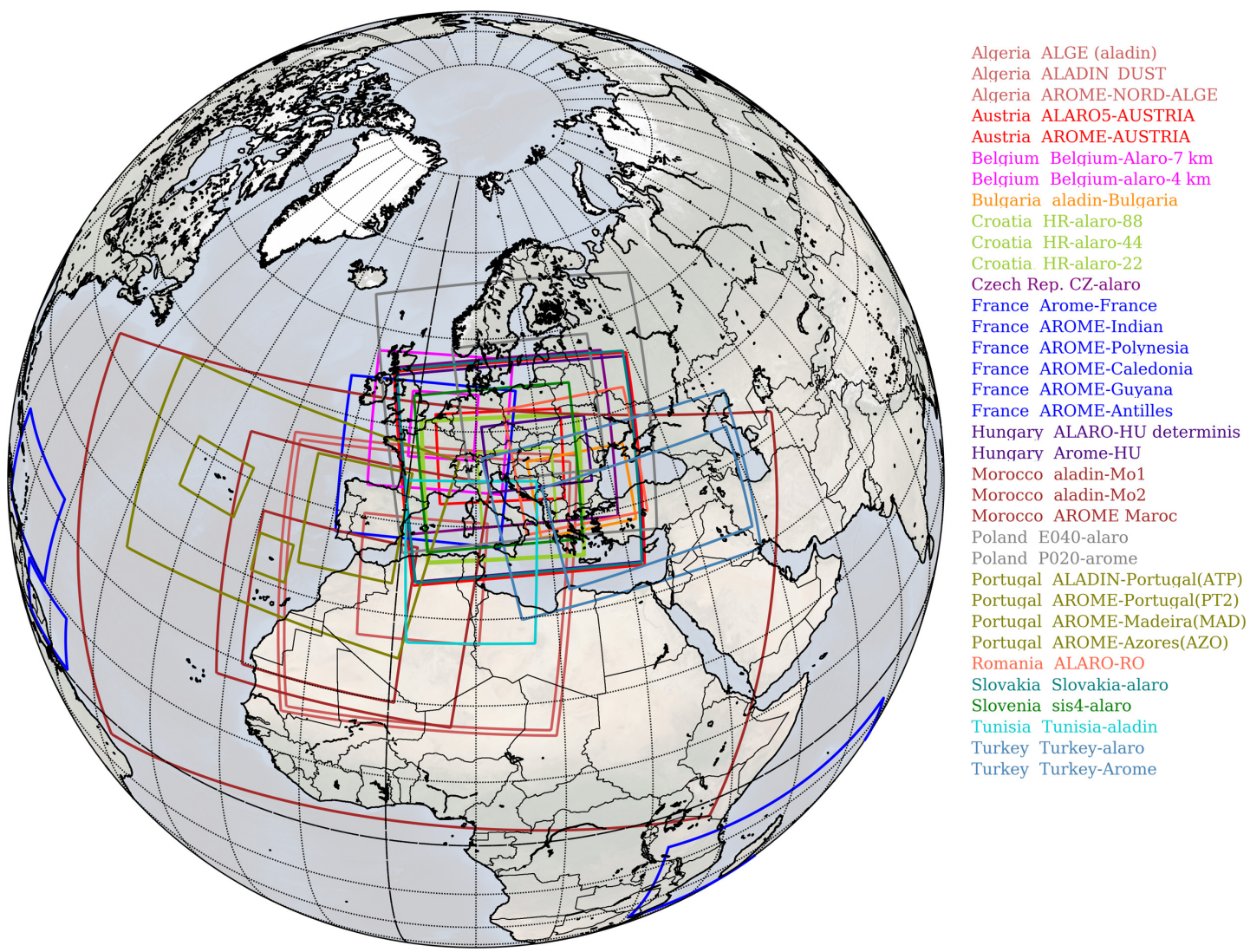

Figure 6. The operational domains of ALADIN System within the ALADIN consortium (situation in April 2017).

ADIN System applications in the partner countries with their main characteristics.

Typical configurations are run with horizontal resolutions of 1.3 and $2.5 \mathrm{~km}$ for AROME and about $4-5 \mathrm{~km}$ for ALARO. Some partners run both configurations in a doublenesting setup: for instance, ALARO (or ALADIN) on a larger domain with a coarser resolution of 4-10 km, driven either by the IFS or ARPEGE global model, and a convectionpermitting AROME or ALARO configuration on a smaller domain focusing on the partner's country and close neighborhoods, that is usually coupled to the intermediate ALARO (or the ALADIN) model configuration.

Currently the ALADIN consortium is installing cycles CY40T1 and CY41T1 that are described in Sect. 3 in its operational applications. As can be seen from Table 5, not all partners have made the switch to the latest $\mathrm{CMC}$ at the time of writing. Although it is strongly encouraged to follow the new cycles, some partners may still use older versions in some cases. For instance some partners may be in an acquisition phase for a new HPC machine in their institute and may therefore postpone an upgrade to the next cycle.

It should also be mentioned that CMCs of the ALADIN System are being used with data assimilation, with ensemble prediction systems (EPSs) and with rapid update cycles for nowcasting purposes. For instance, the AROME CMC is op- erationally implemented in Météo-France's nowcasting system (Auger et al., 2015) and in five Overseas $2.5 \mathrm{~km}$ versions (southwestern Indian Ocean, Caribbean, French Guyana, Polynesia and New Caledonia). A 12-member ensemble prediction system using AROME at $2.5 \mathrm{~km}$ resolution, named PEARO (Bouttier et al., 2016; Raynaud and Bouttier, 2016), is also daily running on Météo-France's computing system. ZAMG also develops a comparable system based on the AROME CMC; see Schellander-Gorgas et al. (2017). A detailed description of the activities regarding data assimilation, EPS and nowcasting within the ALADIN consortium is outside the scope of this paper.

\subsection{Added value}

In terms of local implementation, the operational ALADIN System configurations mostly focus on the need to provide a state-of-the-art forecasting system with convective scale resolution. The goal is to provide forecasters, other production departments in ALADIN national weather services, and eventually stakeholders and users of various types, an added-value forecast of severe weather outbreaks, very local weather patterns and a variety of meteorological output fields and products. A typical example of severe weather of concern is heavy precipitation and strong convection, with their pos- 
Table 5. The configurations of the ALADIN System running in the ALADIN partner countries (as in April 2017), with their nationally used name, horizontal resolution (HRES), domain size, number of vertical levels (NLEV), version of the ALADIN System, coupling model and the used configuration (ALADIN, ALARO, AROME).

\begin{tabular}{|c|c|c|c|c|c|c|c|}
\hline Partner & Operational Model & HRES & Domain size & NLEV & Model version & Coupled with & Configuration \\
\hline Algeria & ALADIN-ALGE & 8.00 & $450 \times 450$ & 70 & CY40T1 & ARPEGE & ALADIN \\
\hline Algeria & ALADIN-DUST & 14.00 & $250 \times 250$ & 70 & CY38T1 & ARPEGE & ALADIN \\
\hline Algeria & AROME-NORD-ALGE & 3.00 & $500 \times 500$ & 41 & CY40T1 & ALADIN-ALGE & AROME \\
\hline Austria & ALARO5-AUSTRIA & 4.82 & $540 \times 600$ & 60 & CY36T1 & IFS & ALARO \\
\hline Austria & AROME-AUSTRIA & 2.50 & $432 \times 600$ & 90 & CY40T1 & IFS & AROME \\
\hline Belgium & Belgium-Alaro-7km & 6.97 & $240 \times 240$ & 46 & CY38T1 & ARPEGE & ALARO \\
\hline Belgium & Belgium-alaro-4km & 4.01 & $181 \times 181$ & 46 & CY38T1 & ARPEGE & ALARO \\
\hline Bulgaria & aladin-Bulgaria & 7.00 & $144 \times 180$ & 70 & CY38T1 & ARPEGE & ALADIN \\
\hline Croatia & HR-alaro-88 & 8.00 & $216 \times 240$ & 37 & CY38T1 & IFS & ALARO \\
\hline Croatia & HR-alaro-44 & 4.00 & $432 \times 480$ & 73 & CY38T1 & IFS & ALARO \\
\hline Croatia & HR-alaro-22 & 2.00 & $450 \times 450$ & 37 & CY36T1 & HR-alaro-88 & ALARO \\
\hline Croatia & HR-alaro-HRDA & 2.00 & $450 \times 450$ & 15 & CY38T1 & HR-alaro-88 & ALARO \\
\hline Czech Rep. & CZ-alaro & 4.71 & $432 \times 540$ & 87 & CY38T1 & ARPEGE & ALARO \\
\hline France & Arome-France & 1.30 & $1440 \times 1536$ & 90 & CY41T1 & ARPEGE & AROME \\
\hline France & AROME-Indean Ocean & 2.50 & $900 \times 1600$ & 90 & CY41T1 & IFS & AROME \\
\hline France & AROME-Polynesia & 2.50 & $600 \times 600$ & 90 & CY41T1 & IFS & AROME \\
\hline France & AROME-Caledonia & 2.50 & $600 \times 600$ & 90 & CY41T1 & IFS & AROME \\
\hline France & AROME-Guyana & 2.50 & $384 \times 500$ & 90 & CY41T1 & IFS & AROME \\
\hline France & AROME-Caribbean & 2.50 & $576 \times 720$ & 90 & CY41T1 & IFS & AROME \\
\hline Hungary & ALARO-HU determinis & 7.96 & $320 \times 360$ & 49 & CY38T1 & IFS & ALARO \\
\hline Hungary & Arome-HU & 2.50 & $320 \times 500$ & 60 & CY38T1 & IFS & AROME \\
\hline Morocco & Aladin-NORAF & 18.00 & $324 \times 540$ & 70 & CY41T1 & ARPEGE & ALADIN \\
\hline Morocco & ALADIN Maroc & 7.50 & $400 \times 400$ & 70 & CY41T1 & ARPEGE & ALADIN \\
\hline Morocco & ALADIN Ma 3D-Var & 10.00 & $320 \times 320$ & 60 & CY36T1 & ARPEGE & AROME \\
\hline Morocco & AROME Maroc & 2.50 & $800 \times 800$ & 60 & CY41T1 & ALADIN Ma 3D-Var & AROME \\
\hline Poland & E040-alaro & 4.00 & $800 \times 800$ & 60 & CY40T1 & ARPEGE & ALARO \\
\hline Poland & P020-arome & 2.04 & $810 \times 810$ & 60 & CY40T1 & E040-alaro & AROME \\
\hline Portugal & ALADIN-Portugal(ATP) & 9.00 & $288 \times 450$ & 46 & CY38T1 & ARPEGE & ALADIN \\
\hline Portugal & AROME-Portugal(PT2) & 2.50 & $540 \times 480$ & 46 & CY38T1 & ARPEGE & AROME \\
\hline Portugal & AROME-Madeira(MAD) & 2.50 & $200 \times 192$ & 46 & CY38T1 & ARPEGE & AROME \\
\hline Portugal & AROME-Azores(AZO) & 2.50 & $270 \times 360$ & 46 & CY38T1 & ARPEGE & AROME \\
\hline Romania & ALARO-RO & 6.50 & $240 \times 240$ & 60 & CY40T1 & ARPEGE & ALARO \\
\hline Slovakia & Slovakia-alaro & 4.50 & $576 \times 625$ & 63 & CY36T1 & ARPEGE & ALARO \\
\hline Slovenia & sis4-alaro & 4.40 & $432 \times 432$ & 87 & CY38T1 & IFS & ALARO \\
\hline Tunisia & Tunisia-ALADIN & 7.50 & $216 \times 270$ & 70 & CY38T1 & ARPEGE & ALADIN \\
\hline Turkey & Turkey-alaro & 4.50 & $450 \times 720$ & 60 & CY38T1 & ARPEGE & ALARO \\
\hline Turkey & Turkey-Arome & 2.50 & $512 \times 1000$ & 60 & CY38T1 & ARPEGE & AROME \\
\hline
\end{tabular}

sible associated features like severe wind gusts, heavy hail or flooding.

The progressive increase in resolution led to more realistic forecasts of convective systems. As an example, Fig. 7 displays the number of convective cells as a function of their size, represented by the cloud-covered area, derived from the observations of the French radar network, the $2.5 \mathrm{~km}$ version of AROME-France and the newer $1.3 \mathrm{~km}$ version (Fig. 7 is adapted from Brousseau et al., 2016). The new version of AROME provides a more realistic distribution of cell size, with both a larger amount of small cells, as suggested by the radar data, and a slight decrease in the number of large ones. Brousseau et al. (2016) also reported an improved timing of the diurnal cycle of convective activity, improved scores of accumulated rainfall thresholds or wind gusts.

The new versions of the ALADIN System are also verified for specific past cases that are of primary interest, demonstrating added value of the high-resolution forecasts with respect to the global model or with respect to the previous versions. Figure 8 shows an example of a warning of the AROME configuration AROME-Aut ${ }^{12}$ running in Zentralanstalt für Meteorologie und Geodynamik (ZAMG) (see

\footnotetext{
${ }^{12}$ This version uses a combined 3D-Var for the atmosphere and an optimal interpolation for the surface to create the initial conditions. The lateral boundary conditions with hourly resolution are created from the IFS high-resolution (HRES) model.
} 


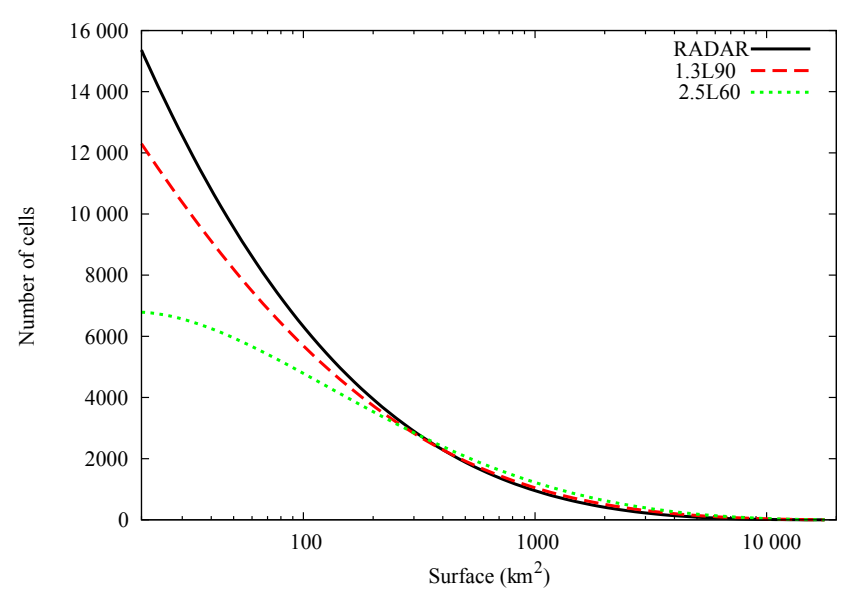

Figure 7. Distribution of the number of convective cells against their size represented by an estimate of the cloudy area, as derived from the data of the French radar network $(40 \mathrm{dBz}$ reflectivity detection level, solid black curve), from the $1.3 \mathrm{~km}, 90$-level AROME version (dashed red curve) and from the $2.5 \mathrm{~km}$, 60-level AROME (dotted green curve). The statistics have been aggregated over 48 convective days of 2012. Adapted from Brousseau et al. (2016).

Table 5). It is the 1 June 2016 forecast of a flash flood event that took place at the border region between Austria and Germany. Figure $8 \mathrm{a}$ shows the $24 \mathrm{~h}$ accumulated INCA precipitation analysis (combination of rain gauge and radar data; see Haiden et al., 2011) for Austria and the surrounding regions. It can be seen that the observed values exceeded $100 \mathrm{~mm}$ in $24 \mathrm{~h}$. However, the intensity of the flooding observed in this region and the river gauge measurements indicate that local maxima of precipitation must have been significantly higher than $100 \mathrm{~mm}$ per $24 \mathrm{~h}$ up to even $200 \mathrm{~mm}$ per $24 \mathrm{~h}$. Figure $8 \mathrm{~b}$ and $\mathrm{c}$ represent the corresponding precipitation forecast for AROME-Aut and IFS HRES. One can see that the localization of the strongest activity is captured well in both models, AROME and IFS, but the overall amplitude is much better simulated by AROME-Aut. This is confirmed when considering the area mean and area max values of INCA, AROME-Aut and IFS HRES in Table 6. The area values shown are computed for a rectangular region indicated by a yellow square in Fig. 8 .

Efforts are made to steadily increase the resolutions of the applications. For instance, the operational viability of the CY40T1 ALARO CMC is tested at kilometer-scale resolution over Belgium by the Royal Meteorological Institute of Belgium (RMI), as represented the lower part of the diagram in Fig. 2. It is a regular $1.3 \mathrm{~km}$ grid on a Lambert projection, with its center at $50.57^{\circ} \mathrm{N}, 4.55^{\circ} \mathrm{E}$, with 588 physical grid points in the east-west and north-south directions, and with 87 vertical layers. This ALARO CMC run on a kilometer scale was evaluated for a severe convective storm of 18 August 2011 causing casualties at the Pukkelpop mu-

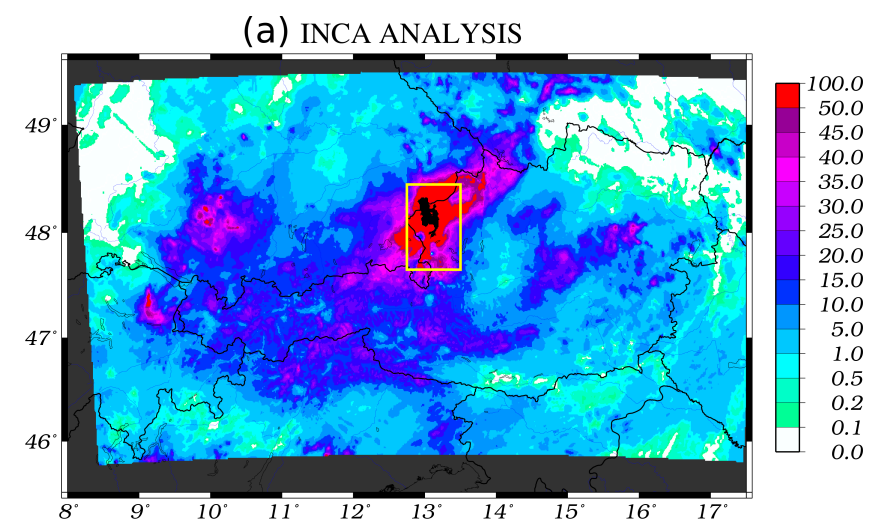

(b) AROME FORECAST

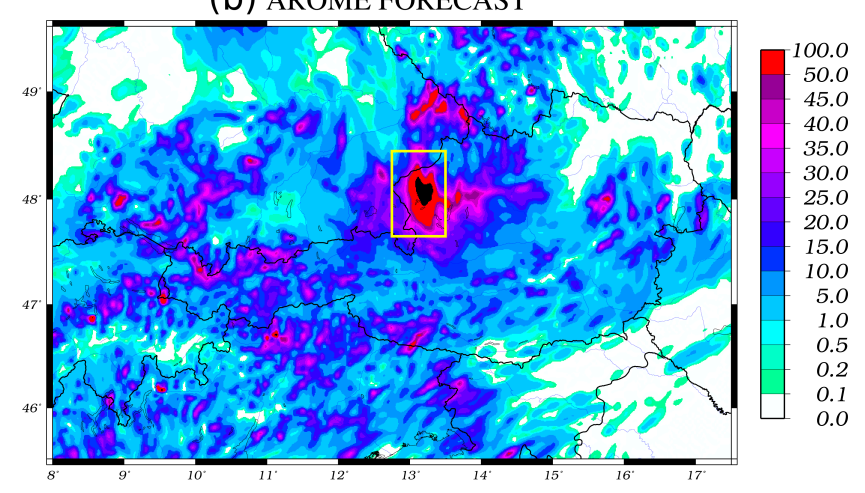

(c) ECMWF/IFS FORECAST

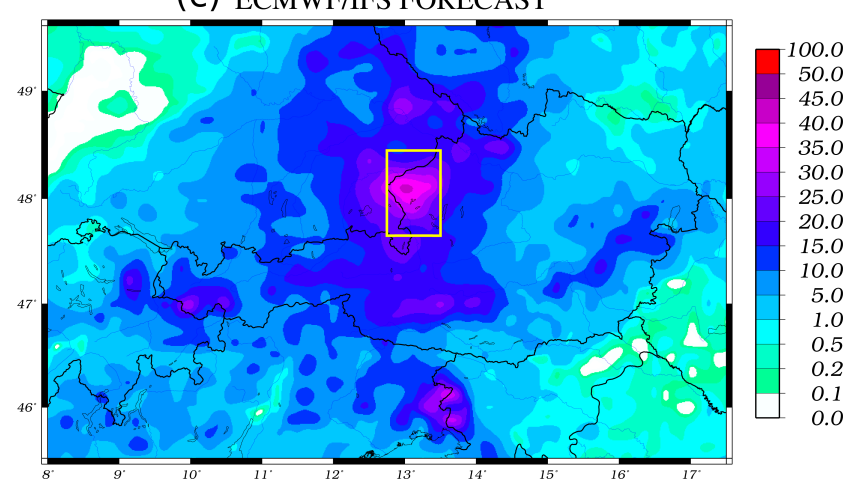

Figure 8. (a) INCA precipitation analysis for the $24 \mathrm{~h}$ period of 31 May 2016 12:00 UTC to 1 June 2016 12:00 UTC, (b) AROMEAut $24 \mathrm{~h}$ accumulated precipitation forecast for the period of 31 May 2016 12:00 UTC to 1 June 2016 12:00 UTC (initialization time: 31 May 2016 12:00 UTC) and (c) IFS-HRES 24 h accumulated precipitation forecast for the period of 31 May 2016 12:00 UTC to 1 June 2016 12:00 UTC (initialization time: 31 May 2016 12:00 UTC).

sic festival in Belgium; see De Meutter et al. (2015). Figure 9 presents the accumulated precipitation between +6 and $+30 \mathrm{~h}$ forecast ranges simulated by ALARO and observed with the radar of Wideumont of the Royal Meteorological Institute, Belgium (Delobbe and Holleman, 2006). The red dot 
Table 6. $24 \mathrm{~h}$ accumulated area mean and area max values for the region (longitude/latitude: 12.75-13.5/47.65-48.45) for INCA, AROME-aut and IFS-HRES.

\begin{tabular}{lrr}
\hline & $\begin{array}{r}\text { Area mean } \\
(\mathrm{mm} \text { per 24 } \mathrm{h})\end{array}$ & $\begin{array}{r}\text { Area max } \\
(\mathrm{mm} \text { per 24 } \mathrm{h})\end{array}$ \\
\hline INCA analysis & 58.0 & 141.6 \\
AROME-Aut & 41.5 & 137.5 \\
IFS HRES & 26.6 & 41.3 \\
\hline
\end{tabular}

presents the location of the Pukkelpop music festival. The newer version of ALARO reproduces the location and the amount of precipitation for this storm better than the current operational version that is run at $4 \mathrm{~km}$ resolution.

\subsection{Tailor-made configurations}

Configurations of ALADIN System are used by the partners of the consortium for scientific studies. In many cases, the partners rely on their own expertise to adapt the versions of the ALADIN System to develop tailor-made tools for their national needs.

As an illustration, the configurations of the ALADIN System of Croatia (shown in Table 5) have been used for dynamical adaptation of the wind field to $2 \mathrm{~km}$ resolution since 2000; see Ivatek-Šahdan and Tudor (2004).

ALARO-HRDA has had a large success in forecasting spatial and temporal variability of local windstorm Bura (Grisogono and Belušić, 2009). The high-resolution wind field forecast has been an essential element in issuing warnings for hazardous weather and safety of traffic at sea and on land. ALARO-HRDA was used to create a wind atlas of Croatia by downscaling the ECMWF ERA40 reanalysis data (Uppala et al., 2005) through ALARO-88 as an intermediate step, using an older version of the ALARO configuration.

There are episodes of severe Bura associated to local dynamical phenomena that require high-resolution forecasts using nonhydrostatic dynamics and complete ALARO physics package (Tudor and Ivatek-Šahdan, 2010). The ALARO configuration has been adapted by the Meteorological and Hydrological Service to run at a resolution of $2 \mathrm{~km}$, the so-called HR-alaro-22 (indicated in Table 5). It is in the operational suite since July 2011. The wind field forecast is improved (Fig. 10) for local short-burst events. This ALARO configuration of the ALADIN System uses the ALADIN NH dynamics, the ALARO physics package, the SSDFI for initialization and is coupled to the global model with a $1 \mathrm{~h}$ couplingupdate frequency.

Configurations of the ALADIN System are still used for applications where mesoscale applications are required: for instance, there are adapted regional-climate model versions of ALADIN (Déqué and Somot, 2008; Colin et al., 2010) and ALARO (Giot et al., 2016). An ALADIN configuration is used by the UERRA project (FP7 project) to provide an (a)

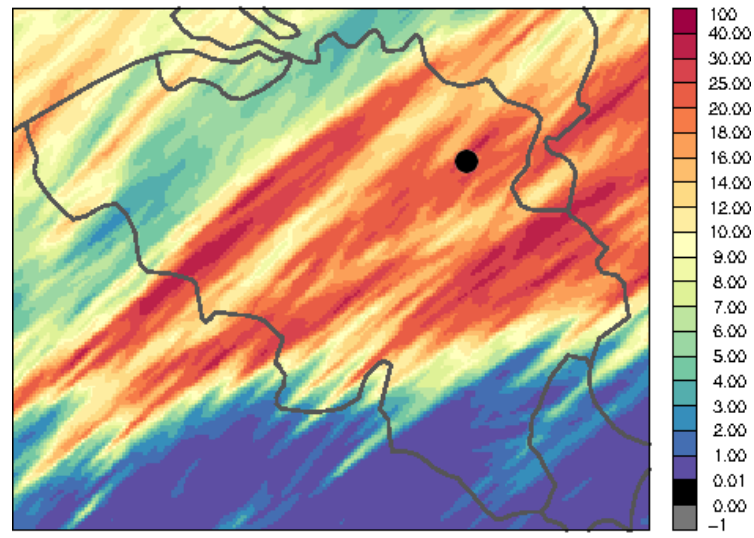

(b)

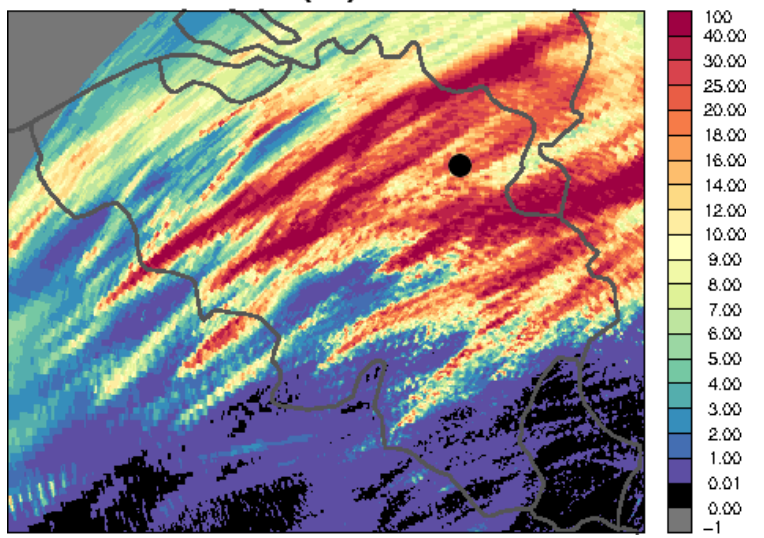

Figure 9. The accumulated precipitation between +6 and $+30 \mathrm{~h}$ forecast range (a) simulated by ALARO and (b) observed with the radar of Wideumont, Belgium.

atmospheric European reanalysis (3D-Var) at $11 \mathrm{~km}$ over Europe for the period $1961-2015^{13}$.

\section{Discussion and outlook}

The aim of this paper was to describe the current state of the forecast model configurations of the ALADIN System and review the rationale behind the scientific options made in the past developments of the ALADIN System. Given the increase in choices in the model configurations, the ALADIN consortium introduced the notion of canonical model configurations. These are privileged, physically consistent configurations that are intensively validated and for which support from the consortium is provided to implement them as operational applications in the ALADIN partner countries. The status of the current two CMCs AROME and ALARO was described and a status report on their validation and implementation in the ALADIN partners' NWP applications was

\footnotetext{
${ }^{13}$ See its project web site http://www.uerra.eu.
} 


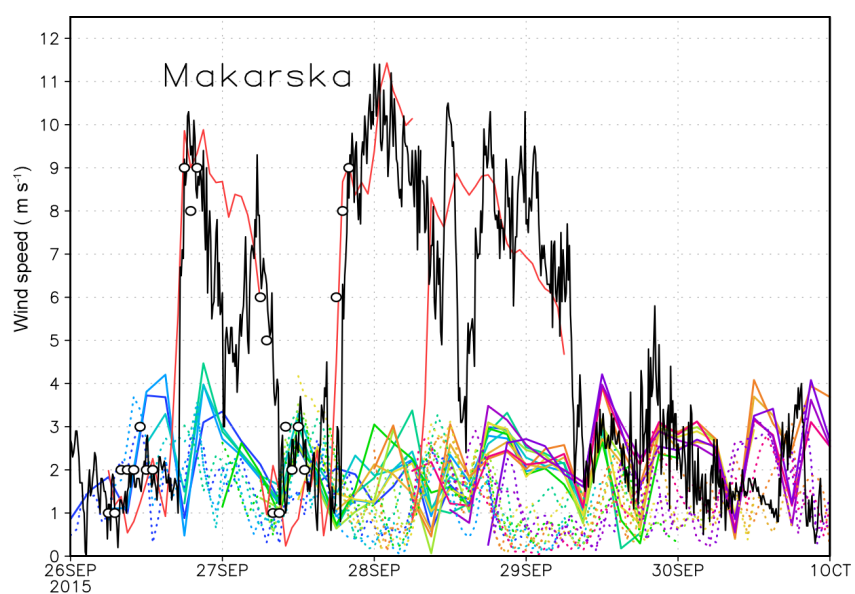

Figure 10. Wind speed in Makarska $\left(43.28^{\circ} \mathrm{N}, 17.02^{\circ} \mathrm{E}\right)$ from 00:00 UTC 26 September 2015 until 00:00 UTC 1 October 2015, measured by the local automatic station with 10 min intervals (black), the local synoptic station (black circles) and forecasts: HR-alaro-22 (red), HR-alaro-88 (full lines) and HR-alaro-HRDA (dashed) are plotted in rainbow sequence depending on the analysis time (blue for the run starting at 00:00 UTC 26 September 2015, light blue for 06:00 UTC the same day, etc.).

given. While doing so this paper clarified the meaning of the acronyms used within the ALADIN consortium.

The scope of the present paper was limited to the forecast model configurations, excluding data assimilation, EPS perturbation methods, post-processing software, scripting systems and so forth, but relevant references to these systems were given throughout the paper without aiming to be exhaustive.

The ALADIN consortium provides a platform for the ALADIN members for organizing optional ${ }^{14}$ activities related to numerical weather prediction. This can be done by individual members or in more intense optional multilateral collaborations. The applications range from nowcasting tools and specific academic case studies, to past and future climate simulations. Long model runs are used for creating high-resolution wind-climate atlases.

Codes developed within the context of the cooperation agreement with the HIRLAM consortium have been colloquially called HARMONIE ${ }^{15}$ in the past. Recently Bengtsson et al. (2017) clarified the meaning of the acronym HARMONIE. HIRLAM adapted the AROME CMC to create its HIRLAM reference configuration and this is called the HARMONIE-AROME configuration. It has been decided to limit the meaning of the acronym HARMONIE to this con-

\footnotetext{
${ }^{14}$ Optional activities mean that the ALADIN consortium does not per se, today, provides coordination for these activities among its members, but facilitates them through the management and the delivery of the codes of the ALADIN System.

${ }^{15}$ HARMONIE stands for HIRLAM ALADIN Research on Meso-scale Operational NWP in Euromed.
}

figuration only. In other words, the acronym HARMONIE does not cover to the configurations of the ALADIN System. The model configurations used in Termonia et al. (2012) were configurations of the ALADIN System. Of course, the schemes presented in that paper can also be applied in the HARMONIE-AROME configuration but they should not be understood as being restricted solely to the HARMONIEAROME configuration.

The shared codes are undergoing a number of code modernizations driven by the strong will to keep them fit both for optimal use of upcoming high-performance computing architectures and for further scientific and meteorological evolutions. This is a significant investment, performed together with ECMWF. It involves the use of object-oriented software layers to provide a further abstraction level in data assimilation on the one hand, and in compute grids on the other hand, accompanied by disentangling and modularization, optimization and portability issues (including reliability on massively parallel HPC). Extra work on the development of scripts for data assimilation is planned. There are no shortterm reasons to abandon the spectral numerical techniques of the dynamical core of the ALADIN System as long as the inherent scalability weakness is more than balanced by the advantage of being able to run with large Courant numbers. Nonetheless, the ALADIN consortium carries out research on scalability and efficiency issues including the study of local discretization methods with research studies ranging from adapting the semiimplicit problem formulation and solution to try and keep the large Courant number time-stepping, to being able to solve the same equations using a HEVI (horizontally explicit, vertically implicit) scheme, the latter being a kind of fall-back solution.

Code availability. The ALADIN Codes, along with all their related intellectual property rights, are owned by the members of the ALADIN consortium and are shared with the members of the HIRLAM consortium in the frame of a cooperation agreement. This agreement allows each member of either consortium to license the shared ALADIN-HIRLAM codes to academic institutions of their home country for noncommercial research.

Access to the codes of the ALADIN System can be obtained by contacting one of the member institutes mentioned in the introduction of this paper or by submitting a request in the Contact link below the page of the ALADIN website (http://www.umr-cnrm.fr/ aladin/) and the access will be subject to signing a standardized ALADIN-HIRLAM license agreement.

Competing interests. The authors declare that they have no conflict of interest.

Acknowledgements. The present paper was substantially improved by taking into account many pertinent comments from Philippe Bougeault, Per Unden and the anonymous reviewer. 
The activities of the ALADIN consortium started in 1991 after an initiative taken by Météo-France. The current system is the result of the contributions of many experts from the ALADIN, the ARPEGE and the IFS communities. The merits of the authors in the developments of the ALADIN System are small compared to this. The present paper is meant to give a status review of the current system according to our best efforts. While the list of contributors is too long to be acknowledged here, we point out the unique contributions of the late Jean-François Geleyn. He was the driving force behind the creation of the ALADIN consortium and he was the leading scientist of the developments of the ALADIN System. His vision further enabled the training of many young scientists throughout Europe and northern Africa in state-of-the-art numerical weather prediction. When he passed away in 2015 the consortium lost an exceptional mind. We dedicate this paper to his memory.

Edited by: Paul Ullrich

Reviewed by: Per Unden and one anonymous referee

\section{References}

ALADIN international team: The ALADIN project: Mesoscale modelling seen as a basic tool for weather forecasting and atmospheric research, WMO Bull., 46, 317-324, 1997.

Amodei, M., Sanchez, I., and Stein, J.: Verification of the French operational high-resolution model AROME with the regional Brier probability score, Meteorol. Appl., 22, 731-745, https://doi.org/10.1002/met.1510, 2015.

Auger, L., Dupont, O., Hagelin, S., Brousseau, P., and Brovelli, P.: AROME-NWC: a new nowcasting tool based on an operational mesoscale forecasting system, Q. J. Roy. Meteor. Soc., 141, 1603-1611, https://doi.org/10.1002/qj.2463, 2015.

Bauer, P., Thorpe, A., and Brunet, G.: The quiet revolution of numerical weather prediction, Nature, 525, 47-55, https://doi.org/10.1038/nature14956, 2015.

Bazile, E., Marquet, P., Bouteloup, Y., and Bouyssel, F.: The Turbulent Kinetic Energy (TKE) scheme in the NWP models at Météo-France, ECMWF Workshop Proceedings, Workshop on Diurnal cycles and the stable boundary layer, 7-10 November 2011, Reading, UK, 127-136, 2011.

Bechtold, P., Cuijpers, J., Mascart, P., and Trouilhet, P.: Modelling of trade-wind cumuli with a low-order turbulence model-toward a unified description of $\mathrm{Cu}$ and Sc clouds in meteorological models, J. Atmos. Sci., 52, 455-463, 1995.

Bechtold, P., Bazile, E., Guichard, F., Mascart, P., and Richard, E.: A mass flux convection scheme for regional and global models, Q. J. Roy. Meteor. Soc., 127, 869-886, 2001.

Belamari, S. and Pirani, A.: Validation of the optimal heat and momentum fluxes using the ORCA2-LIM global ocean-ice model. Marine environment and security for the European area. Integrated Project (MERSEA IP), Deliverable D4.1.3, 88 pp., 2007.

Bénard, P.: Stability of Semi-Implicit and Iterative CenteredImplicit Time Discretizations for Various Equation Systems Used in NWP, Mon. Weather Rev., 131, 2479-2491, 2003.

Bénard, P., Laprise, R., Vivoda, J., and Smolíková, P.: Stability of Leapfrog Constant-Coefficients Semi-Implicit Schemes for the
Fully Elastic System of Euler Equations: Flat-Terrain Case, Mon. Weather Rev., 132, 1306-1318, 2004.

Bénard, P., Mašek, J., and Smolíková, P.: Stability of leapfrog constant-coefficient semi-implicit schemes for the fully elastic system of Euler equations: Case with orography, Mon. Weather Rev., 133, 1065-1075, 2005.

Bénard, P., Vivoda, J., Mašek, J., Smolíková, P., Yessad, K., Smith, C., Brožková, R., and Geleyn, J.-F.: Dynamical kernel of the Aladin-NH spectral limited-area model: Revised formulation and sensitivity experiments., Q. J. Roy. Meteor. Soc., 136, 155-169, 2010.

Bengtsson, L., Andrae, U., Aspelien, T., Batrak, Y., Calvo, J., de Rooy, W., Gleeson, E., Hansen-Sass, B., Homleid, M., Hortal, M., Ivarsson, K.-I., Lenderik, G., Niemelä, S., Nielsen, K. P., Onvlee, J., Rontu, L., Samuelsson, P., Muñoz, D. S., Subias, A., Tijm, S., Tol, V., Yang, X., and Køltzow, M. Ø.: The HARMONIE-AROME model configuration in the ALADINHIRLAM NWP system, Mon. Weather Rev., 145, 1919-1935, https://doi.org/10.1175/MWR-D-16-0417.1, 2017.

Bougeault, P.: Cloud-ensemble relations based on the gamma probability distribution for the higher-order models of the planetary boundary layer, J. Atmos. Sci., 39, 2691-2700, 1982.

Bougeault, P.: A simple parameterization of the largescale effects of cumulus convection, Mon. Weather Rev., 113, 2108-2121, https://doi.org/10.1175/15200493(1985)113<2108:ASPOTL>2.0.CO;2, 1985.

Bougeault, P. and Lacarrere, P.: Parameterization of orographyinduced turbulence in a meso-beta-scale model, Mon. Weather Rev., 117, 1870-1888, 1989.

Bouteloup, Y. and Toth, H.: Refinements in the parameterisation of radiative exchanges, ALADIN Newsletter, 23, 178-183, 2003.

Bouteloup, Y., Bouyssel, F., and Marquet, P.: Improvements of Lopez's progonostic large scale cloud and precipitation scheme, Météo-France, ALADIN Newsletter, 28, 66-73, 2005.

Bouteloup, Y., Seity, Y., and Bazile, E.: Description of the sedimentation scheme used operationally in all Météo-France NWP models, Tellus A, 63, 300-311, 2011.

Bouttier, F., Raynaud, L., Nuissier, O., and Ménétrier, B.: Sensitivity of the AROME ensemble to initial and surface perturbations during HyMeX, Q. J. Roy. Meteor. Soc., 142, 390-403, https://doi.org/10.1002/qj.2622, 2016.

Boyd, J. P.: Limited-Area Fourier Spectral Models and Data Analysis Schemes: Windows, Fourier Extension, Davies Relaxation, and All That, Mon. Weather Rev., 133, 2030-2042, https://doi.org/10.1175/MWR2960.1, 2005.

Brousseau, P., Seity, Y., Ricard, D., and Léger, J.: Improvement of the forecast of convective activity from the AROME-France system, Q. J. Roy. Meteor. Soc., 142, 2231-2243, 2016.

Bubnová, R., Hello, G., Bénard, P., and Geleyn, J.-F.: Integration of the fully elastic equations cast in the hydrostatic pressure terrainfollowing coordinate in the framework of the arpege/aladin nwp system, Mon. Weather Rev., 123, 515-535, 1995.

Canuto, V. M., Cheng, Y., and Howard, A. M.: Nonlocal ocean mixing model and a new plume model for deep convection, Ocean Model., 16, 28-46, https://doi.org/10.1016/j.ocemod.2006.07.003, 2007.

Canuto, V. M., Cheng, Y., Howard, A. M., and Esau, I. N.: Stably stratified flows: A model with no Ri(cr), J. Atmos. Sci., 65, 24372447, https://doi.org/10.1175/2007JAS2470.1, 2008. 
Carabajal, C., Harding, D., Boy, J.-P., Danielson, J. , Gesch, D., and Suchdeo, V.: Evaluation of the global multi-resolution terrain elevation data 2010 (GMTED2010) using ICESat geodetic control, in: SPIE 8286, International Symposium on Lidar and Radar Mapping 2011: Technologies and Applications, Nanjing, China, 2011.

Catry, B., Geleyn, J.-F., Tudor, M., Bénard, P., and Trojáková, A.: Flux-conservative thermodynamic equations in a mass-weighted framework, Tellus A, 59, 71-79, 2007.

Catry, B., Geleyn, J.-F., Bouyssel, F., Cedilnik, J., Brožková, R., Derková, M., and Mladek, R.: A new sub-grid scale lift formulation in a mountain drag parameterisation scheme, Meteorol. Z., 17, 193-208, https://doi.org/10.1127/0941-2948/2008/0272, 2008.

Charnock, H.: Wind stress over a water surface, Q. J. Roy. Meteor. Soc., 81, 639-640, 1955.

Cheng, Y., Canuto, V. M., and Howard, A. M.: An improved model for the turbulent PBL, J. Atmos. Sci., $\quad 59, \quad 1550-1565, \quad$ https://doi.org/10.1175/15200469(2002)059<1550:AIMFTT>2.0.CO;2, 2002.

Coiffier, J.: Fundamentals of Numerical Weather Prediction, Cambridge University Press, Cambridge, UK, https://doi.org/10.1017/CBO9780511734458, 2011.

Colin, J., Déqué, M., Radu, R., and Somot, S.: Sensitivity study of heavy precipitations in Limited Area Model climate simulation: influence of the size of the domain and the use of the spectral nudging technique, Tellus A, 62, 591-604, https://doi.org/10.1111/j.1600-0870.2010.00467.x, 2010.

Courtier, P. and Geleyn, J.-F.: A global numerical weather prediction model with variable resolution: Application to the shallow model equations, Q. J. Roy. Meteor. Soc., 114, 1321-1346, 1988.

Courtier, P., Freydier, C., Geleyn, J.-F., Rabier, F., and Rochas, M.: The ARPEGE project at Météo-France, Proceedings of 1991 ECMWF Seminar on Numerical Methods in Atmospheric Models, ECMWF, Reading, UK, 193-231, 1991.

Cuxart, J., Bougeault, P., and Redelsberger, J.-L.: A turbulence scheme allowing for mesoscale and large-eddy simulations, Q. J. Roy. Meteor. Soc., 126, 1-30, 2000.

Davies, H. C.: A lateral boundary formulation for multilevel prediction models, Q. J. Roy. Meteor. Soc., 102, 405-418, 1976.

Davies, H. C.: Limitations of some common lateral boundary schemes used in regional NWP models, Mon. Weather Rev., 111, 1002-1012, 1983.

Degrauwe, D., Caluwaerts, S., Voitus, F., Hamdi, R., and Termonia, P.: Application of Boyd's Periodization and Relaxation Method in a Spectral Atmospheric Limited-Area Model. Part II: Accuracy Analysis and Detailed Study of the Operational Impact, Mon. Weather Rev., 140, 3149-3162, https://doi.org/10.1175/MWR-D-12-00032.1, 2012.

Degrauwe, D., Seity, Y., Bouyssel, F., and Termonia, P.: Generalization and application of the flux-conservative thermodynamic equations in the AROME model of the ALADIN system, Geosci. Model Dev., 9, 2129-2142, https://doi.org/10.5194/gmd-9-21292016, 2016.

Delobbe, L. and Holleman, I.: Uncertainties in radar echo top heights used for hail detection, Meteor. Appl., 13, 361-374, https://doi.org/10.1017/S1350482706002374, 2006.

De Meutter, P., Gerard, L., Smet, G., Hamid, K., Hamdi, R., Degrauwe, D., and Termonia, P.: Predicting Small-Scale,
Short-Lived Downbursts: Case Study with the NWP LimitedArea ALARO Model for the Pukkelpop Thunderstorm, Mon. Weather Rev., 143, 742-756, https://doi.org/10.1175/MWR-D14-00290.1, 2015.

Déqué, M. and Somot, S.: Extreme precipitation and high resolution with Aladin, Idöjaras Quaterly Journal of the Hungarian Meteorological Service, 112, 179-190, 2008.

de Rooy, W., de Bruijn, C., Tijm, S., Neggers, R., Siebesma, P., and Barkmeijer, J.: Experiences with HARMONIE at KNMI, HIRLAM Newsletter, 56, 21-29, 2010.

De Troch, R., Hamdi, R., Van de Vyver, H., Geleyn, J.-F., and Termonia, P.: Multiscale Performance of the ALARO-0 Model for Simulating Extreme Summer Precipitation Climatology in Belgium, J. Climate, 26, 8895-8915, https://doi.org/10.1175/JCLID-12-00844.1, 2013.

Durán, I. B., Geleyn, J., and Váňa, F.: A Compact Model for the Stability Dependency of TKE Production-Destruction-Conversion Terms Valid for the Whole Range of Richardson Numbers, J. Atmos. Sci., 71, 3004-3026, https://doi.org/10.1175/JAS-D-130203.1, 2014.

Ebert, E. and Curry, J. A.: A parameterization of ice cloud optical properties for climate models, J. Geophys. Res., 97, 3831-3835, 1992.

Field, P. R., Brožková, R., Chen, M., Dudhia, J., Lac, C., Hara, T., Honnert, R., Olson, J., Siebesma, P., de Roode, S., Tomassini, L., Hill, A., and McTagart-Cowan, R.: Exploring the convective grey zone with regional simulations of a cold air outbreak, Q. J. Roy. Meteor. Soc., 143, 2537-2555, https://doi.org/10.1002/qj.3105, 2017.

Fischer, C., Montmerle, T., Berre, L., Auger, L., and Ştefănescu, S. E.: An overview of the variational assimilation in the ALADIN/France numerical weatherprediction system, Q. J. Roy. Meteor. Soc., 131, 3477-3492, https://doi.org/10.1256/qj.05.115, 2005.

Fouquart, Y. and Bonnel, B.: Computations of solar heating of the earth's atmosphere: A new parameterization, Beitr. Phys. Atmos., 53, 35-62, 1980.

Geleyn, J.-F., Váňa, F., Cedilnik, J., Tudor, M., and Catry, B.: An intermediate solution between diagnostic exchange coefficients and prognostic TKE methods for vertical turbulent transport, in: CAS/JSC WGNE "Blue Book" annual report: Research Activities in Atmospheric and Ocean Modelling, edited by: Côté, J., 4.11-4.12, 2006.

Geleyn, J.-F., Catry, B., Bouteloup, Y., and Brožková, R.: A statistical approach for sedimentation inside a micro-physical precipitation scheme, Tellus A, 60, 649-662, 2008.

Geleyn, J.-F., Mašek, J., Brožková, R., Kuma, P., Degrauwe, D., Hello, G., and Pristov, N.: Single interval longwave radiation scheme based on the net exchange rate decomposition with bracketing, Q. J. Roy. Meteor. Soc., 143, 1313-1335, https://doi.org/10.1002/qj.3006, 2017.

Gerard, L.: Bulk Mass-Flux Perturbation Formulation for a Unified Approach of Deep Convection at High Resolution, Mon. Weather Rev., 143, 4038-4063, https://doi.org/10.1175/MWRD-15-0030.1, 2015.

Gerard, L. and Geleyn, J.-F.: Evolution of a subgrid deep convection parameterization in a limited area model with increasing resolution, Q. J. Roy. Meteor. Soc., 131, 2293-2312, 2005. 
Gerard, L., Piriou, J.-M., Brožková, R., Geleyn, J.-F., and Banciu, D.: Cloud and precipitation parameterization in a meso-gammascale operational weather prediction model, Mon. Weather Rev., 137, 3960-3977, 2009.

Giot, O., Termonia, P., Degrauwe, D., De Troch, R., Caluwaerts, S., Smet, G., Berckmans, J., Deckmyn, A., De Cruz, L., De Meutter, P., Duerinckx, A., Gerard, L., Hamdi, R., Van den Bergh, J., Van Ginderachter, M., and Van Schaeybroeck, B.: Validation of the ALARO-0 model within the EURO-CORDEX framework, Geosci. Model Dev., 9, 1143-1152, https://doi.org/10.5194/gmd9-1143-2016, 2016.

Grisogono, B. and Belušić, D.: A review of recent advances in understanding the meso- and microscale properties of the severe Bora wind, Tellus A, 61, 1-16, 2009.

Guérémy, J.-F.: A continuous buoyancy based convection scheme: one- and three dimensional validation, Tellus, 63A, 687-706, https://doi.org/10.1111/j.1600-0870.2011.00521.x, 2011.

Hage, J. V. D.: A parametrization of the Wegener-BergeronFindeisen effect, Atmos. Res., 39, 201-214, 1995.

Haiden, T., Kann, A., Wittmann, C., Pistotnik, G., Bica, B., and C, C. G.: The Integrated Nowcasting through Comprehensive Analysis (INCA) System and Its Validation over the Eastern Alpine Region, Weather Forecast., 26, 166-183, 2011.

Hamdi, R., Degrauwe, D., Duerinckx, A., Cedilnik, J., Costa, V., Dalkilic, T., Essaouini, K., Jerczynki, M., Kocaman, F., Kullmann, L., Mahfouf, J.-F., Meier, F., Sassi, M., Schneider, S., Váňa, F., and Termonia, P.: Evaluating the performance of SURFEXv5 as a new land surface scheme for the ALADINcy36 and ALARO-0 models, Geosci. Model Dev., 7, 23-39, https://doi.org/10.5194/gmd-7-23-2014, 2014.

Hamrud, M., Saarinen, S., and Salmond, D.: Implementation of the IFS on a highly parallel scalar system, in: Proceedings of the tenth ECMWF workshop on the use of parallel processors in meteorology, 4-8 November 2002, Reading, UK, World Scientific, Singapore, 74-87, 2012.

Haugen, J. E. and Machenhauer, B.: A spectral Limited-Area Model Formulation with Time-Dependent Boundary Conditions Applied to the Shallow-Water Equations, Mon. Weather Rev., 121, 2618-2630, 1993.

Hogan, R. J. and Illingworth, A. J.: Deriving cloud overlap statistics from radar, Q. J. Roy. Meteor. Soc., 126, 2903-2909, https://doi.org/10.1002/qj.49712656914, 2000.

Iacono, M. J., Delamere, J. S., Mlawer, E. J., Shephard, M. W., Clough, S. A., and Collins, W. D.: Radiative forcing by longlived greenhouse gases: Calculations with the AER radiative transfer models, J. Geophys. Res.-Atmos., 113, D13103, https://doi.org/10.1029/2008JD009944, 2008.

Ivatek-Šahdan, S. and Tudor, M.: Use of high-resolution dynamical adaptation in operational suite and research impact studies, Meteorol. Z., 13, 1-10, 2004.

Jakimow, G., Yakimiw, E., and Robert, A.: An Implicit Formulation for Horizontal Diffusion in Gridpoint Models, Mon. Weather Rev., 120, 124-130, https://doi.org/10.1175/15200493(1992)120<0124:AIFFHD>2.0.CO;2, 1992.

Kain, J. S. and Fritsch, J. M.: A one-dimensional entraining/detraining plume model and its application in convective parameterizations, J. Atmos. Sci., 47, 2784-2802, 1990.

Lafore, J. P., Stein, J., Asencio, N., Bougeault, P., Ducrocq, V., Duron, J., Fischer, C., Héreil, P., Mascart, P., Masson, V., Pinty, J.
P., Redelsperger, J. L., Richard, E., and Vilà-Guerau de Arellano, J.: The Meso-NH Atmospheric Simulation System. Part I: adiabatic formulation and control simulations, Ann. Geophys., 16, 90-109, https://doi.org/10.1007/s00585-997-0090-6, 1998.

Laprise, R.: The Euler equations of motion with hydrostatic pressure as an independent variable, Mon. Weather Rev., 120, 197207, 1992.

Lascaux, F., Richard, E., and Pinty, J.-P.: Numerical simulations of three map IOPs and the associated microphysical processes, Q. J. Roy. Meteor. Soc., 132, 1907-1926, 2006.

Laurantin, O.: ANTILOPE: Hourly rainfall analysis merging radar and rain gauge data, Proceedings of the International Symposium on Weather Radar and Hydrology, 2-8, Grenoble, France, 2008.

Li, D. and Shine, K. P.: A 4-dimensional ozone climatology for UGAMP models, UGAMP (UK Universities Global Atmospheric Modelling Programme) Internal Report No. 35, Meteorology Department, Reading University, 1995.

Lopez, P.: Implementation and validation of a new prognostic large-scale cloud and precipitation scheme for climate and dataassimilation purposes, Q. J. Roy. Meteor. Soc., 128, 229-257, https://doi.org/10.1256/00359000260498879, 2002.

Louis, J.-F.: A parametric model of vertical eddy fluxes in the atmosphere, Bound.-Lay. Meteorol., 17, 187-202, https://doi.org/10.1007/BF00117978, 1979.

Lynch, P.: Initialization using a digital filter, Research Activities in Atmospheric and Ocean Modeling, CAS/JSC Working Group on Numerical Experimentation, Rep. 14, WMO Secretariat, Geneva, Switzerland, 1.5-1.6., 1990.

Lynch, P.: The Dolph-Chebyshev Window: A Simple Optimal Filter, Mon. Weather Rev., 125, 655-660, https://doi.org/10.1175/15200493(1997)125<0655:TDCWAS>2.0.CO;2, 1997.

Lynch, P., Giard, D., and Ivanovici, V.: Improving the Efficiency of a Digital Filtering Scheme for Diabatic Initialization, Mon. Weather Rev., 125, 1976-1982, https://doi.org/10.1175/15200493(1997)125<1976:ITEOAD>2.0.CO;2, 1997.

Malardel, S. and Ricard, D.: An alternative cell-averaged departure point reconstruction for pointwise semi-Lagrangian transport schemes, Q. J. Roy. Meteor. Soc., 141, 2114-2126, 2015.

Marquet, P. and Geleyn, J.-F.: On a general definition of the squared Brunt-Väisälä frequency associated with the specific moist entropy potential temperature, Q. J. Roy. Meteor. Soc., 139, 85100, 2013.

Martin, G. M., Johnson, D. W., and Spice, A.: The measurement and parameterization of effective radius of droplets in warm stratocumulus, J. Atmos. Sci., 51, 1823-1842, 1994.

Mašek, J., Geleyn, J.-F., Brožková, R., Giot, O., Achom, H. O., and Kuma, P.: Single interval shortwave radiation scheme with parameterized optical saturation and spectral overlaps, Q. J. Roy. Meteor. Soc., 142, 304-326, https://doi.org/10.1002/qj.2653, 2016.

Masson, V.: A physically-based scheme for the urban energy budget in atmospheric models, Bound.-Lay. Meteorol., 94, 357-397, 2000.

Masson, V., Champeaux, J.-L., Chauvin, F., Meriguet, C., and Lacaze, R.: A Global Database of Land Surface Parameters at 1-km Resolution in Meteorological and Climate Models, J. Climate, 16, 1261-1282, https://doi.org/10.1175/15200442(2003)16<1261:AGDOLS>2.0.CO;2, 2003. 
Masson, V., Le Moigne, P., Martin, E., Faroux, S., Alias, A., Alkama, R., Belamari, S., Barbu, A., Boone, A., Bouyssel, F., Brousseau, P., Brun, E., Calvet, J.-C., Carrer, D., Decharme, B., Delire, C., Donier, S., Essaouini, K., Gibelin, A.-L., Giordani, H., Habets, F., Jidane, M., Kerdraon, G., Kourzeneva, E., Lafaysse, M., Lafont, S., Lebeaupin Brossier, C., Lemonsu, A., Mahfouf, J.-F., Marguinaud, P., Mokhtari, M., Morin, S., Pigeon, G., Salgado, R., Seity, Y., Taillefer, F., Tanguy, G., Tulet, P., Vincendon, B., Vionnet, V., and Voldoire, A.: The SURFEXv7.2 land and ocean surface platform for coupled or offline simulation of earth surface variables and fluxes, Geosci. Model Dev., 6, 929-960, https://doi.org/10.5194/gmd-6-929-2013, 2013.

Mellor, G. L.: Analytic prediction of the properties of stratified planetary surface layers, J. Atmos. Sci., 30, 1061-1069, https://doi.org/10.1175/15200469(1973)030<1061:APOTPO>2.0.CO;2, 1973.

Mellor, G. L. and Yamada, T.: A hierarchy of turbulence closure models for planetary boundary layers, J. Atmos. Sci., 31, 1791-1806, https://doi.org/10.1175/15200469(1974)031<1791:AHOTCM>2.0.CO;2, 1974.

Mellor, G. L. and Yamada, T.: Development of a turbulence closure model for geophysical fluid problems, Rev. Geophys., 20, 851875, https://doi.org/10.1029/RG020i004p00851, 1982.

Michalakes, J., Govett, M., Benson, R., Black, T., Juang, H., Reinecke, A., and Skamarock, B.: NGGPS level-1 benchmarks and software evaluation. Advanced Computing Evaluation Committee Rep., 22 pp., available at: http://www.nws.noaa.gov/ost/nggps/DycoreTestingFiles/AVEC \%20Level\%201\%20Benchmarking\%20Report\%2008\%20 20150602.pdf (last access: 15 January 2018), 2015.

Mlawer, E. J., Taubman, S. J., Brown, P., Iacono, M. J., and Clough, S. A.: Radiative transfer for inhomogeneous atmospheres: RRTM, a validated correlated-k model for the longwave, J. Geophys. Res., 102, 16663-16682, 1997.

Morcrette, J.-J.: Revision of the clear-sky and cloud radiative properties in the ECMWF model, ECMWF Newsletter, 61, 3-14, 1993.

Morcrette, J.-J.: The surface longwave radiation in the ECMWF Forecast System, ECMWF Technical Memorandum, 339, ECMWF, Reading, UK, 34 pp., 2001.

Morcrette, J.-J. and Fouquart, Y.: The overlapping of cloud layers in shortwave radiation parameterizations, J. Atmos. Sci., 43, 321328, 1986.

Noilhan, J. and Planton, S.: A simple parameterization of land surface processes for meteorological models, Mon. Weather Rev., 117, 536-549, 1989.

Oreopoulos, L., Lee, D., Sud, Y. C., and Suarez, M. J.: Radiative impacts of cloud heterogeneity and overlap in an atmospheric General Circulation Model, Atmos. Chem. Phys., 12, 9097-9111, https://doi.org/10.5194/acp-12-9097-2012, 2012.

Ou, S. C. and Liou, K.-N.: Ice microphysics and climatic temperature feedback, Atmos. Res., 35, 127-138, 1995.

Pergaud, J., Masson, V., Malardel, S., and Couvreux, F.: A parameterization of dry thermals and shallow cumuli for mesoscale numerical weather prediction, Bound.-Lay. Meteorol., 132, 83106, 2009.

Pinty, J.-P. and Jabouille, P.: A mixed-phased cloud parameterization for use in la mesoscale non-hydrostatic model: Simulations of a squall line and of orographic precipitation, Preprints, Conf. on Cloud Physics, 17-21 August 1998, Everett, WA, USA, Am. Meteorol. Soc., 217-220, 1998.

Piriou, J.-M., Redelsperger, J.-L., Geleyn, J.-F., Lafore, J.-P., and Guichard, F.: An approach for convective parameterization with memory, in separating microphysics and transport in grid-scale equations, J. Atmos. Sci., 64, 4127-4139, 2007.

Radnóti, G.: Comments on "A spectral limited-area formulation with time-dependent boundary conditions applied to the shallowwater equations", Mon. Weather Rev., 123, 3122-3123, 1995.

Radnóti, G., Ajjaji, R., Bubnova, R., Caian, M., Cordoneanu, E., Emde, K., Grill, J.-D., Hoffman, J., Horanyi, A., Issara, S., Ivanovici, V., Janousek, M., Joly, A., Moigne, P. L., and Malardel, S.: The spectral limited area model ARPEGE/ALADIN, PWRP report series, 7, 111-117, 1995.

Raynaud, L. and Bouttier, F.: Comparison of initial perturbation methods for ensemble prediction at convective scale, Q. J. Roy. Meteor. Soc., 142, 854-866, https://doi.org/10.1002/qj.2686, 2016.

Ritchie, H., Temperton, C., Simmons, A., Hortal, M., Davies, T., Dent, D., and Hamrud, M.: Implementation of the Semi-Lagrangian Method in a HighResolution Version of the ECMWF Forecast Model, Mon. Weather Rev., 123, 489-514, https://doi.org/10.1175/15200493(1995)123<0489:IOTSLM>2.0.CO;2, 1995.

Ritter, B. and Geleyn, J.-F.: A comprehensive radiation scheme fornumerical weather prediction models with potential applications in climate simulations, Mon. Weather Rev., 120, 303-325, https://doi.org/10.1175/15200493(1992)120<0303:ACRSFN>2.0.CO;2, 1992.

Robert, A. J., Henderson, J., and Turnbull, C.: An implicit scheme for baroclinic models of the atmosphere, Mon. Weather Rev., 100, 329-335, 1972.

Schellander-Gorgas, T., Wang, Y., Meier, F., Weidle, F., Wittmann, C., and Kann, A.: On the forecast skill of a convectionpermitting ensemble, Geosci. Model Dev., 10, 35-56, https://doi.org/10.5194/gmd-10-35-2017, 2017.

Seity, Y., Brousseau, P., Malardel, S., Hello, G., Bénard, P., Bouttier, F., Lac, C., and Masson, V.: The AROME-France ConvectiveScale Operational Model, Mon. Weather Rev., 139, 976-991, https://doi.org/10.1175/2010MWR3425.1, 2011.

Senkova, A. V., Rontu, L., and Savijärvi, H.: Parametrization of orographic effects on surface radiation in HIRLAM, Tellus, 59, 279291, 2007.

Simmons, A. J. and Burridge, D.: An energy and angularmomentum conserving vertical finite-difference scheme and hybrid vertical coordinates, Mon. Weather Rev., 109, 758-766, 1981.

Simmons, A. J., Hoskins, B., and Burridge, D.: Stability of the semiimplicit method of time integration, Mon. Weather Rev., 106, 405-412, 1978.

Smith, C.: Stability analysis and precision aspects of the boundary condition formulation in the non-hydrostatic dynamics and exploration of the alternatives for discrete formulation of the vertical acceleration equation both in Eulerian and semi-Lagrangian time marching schemes, ALADIN Newsletter, No. 21/4, MétéoFrance, Toulouse, France, 46-49, 2002.

Smith, R. N. B.: A scheme for predicting layer clouds and their water content in a general circulation model, Q. J. Roy. Meteor. Soc., 116, 435-460, 1990. 
Soares, P. M. M., Miranda, P. M. A., Siebesma, P., and Teixeira, J.: An eddy-diffusivity/mass-flux parameterization for dry and shallow cumulus convection, Q. J. Roy. Meteor. Soc., 130, 30553079, 2004.

Sukoriansky, S., Galperin, B., and Staroselsky, I.: A quasinormal scale elimination model of turbulent flows with stable stratification, Phys. Fluids, 17, 085107, https://doi.org/10.1063/1.2009010, 2005.

Tegen, I., Hoorig, P., Chin, M., Fung, I., Jacob, D., and Penner, J.: Contribution of different aerosol species to the global aerosol extinction optical thickness: Estimates from model results, J. Geophys. Res., 102, 23895-23915, 1997.

Temperton, C., Hortal, M., and Simmons, A.: A two-time-level semi-Lagrangian global spectral model, Q. J. Roy. Meteor. Soc., 127, 111-127, 2001

Termonia, P.: Monitoring the Coupling-Update Frequency of a Limited-Area Model by Means of a Recursive Digital Filter, Mon. Weather Rev., 132, 2130-2141, https://doi.org/10.1175/15200493(2004)132<2130:MTCFOA>2.0.CO;2, 2004.

Termonia, P.: Scale-Selective Digital-Filtering Initialization, Mon. Weather Rev., 136, 5246-5255, https://doi.org/10.1175/2008MWR2606.1, 2008.

Termonia, P. and Hamdi, R.: Stability and accuracy of the physicsdynamics coupling in spectral models, Q. J. Roy. Meteor. Soc., 133, 1589-1604, 2007.

Termonia, P., Deckmyn, A., and Hamdi, R.: Study of the Lateral Boundary Condition Temporal Resolution Problem and a Proposed Solution by Means of Boundary Error Restarts, Mon. Weather Rev., 137, 3551-3566, https://doi.org/10.1175/2009MWR2964.1, 2009.

Termonia, P., Degrauwe, D., and Hamdi, R.: Improving the Temporal Resolution Problem by Localized Gridpoint Nudging in Regional Weather and Climate Models, Mon. Weather Rev., 139, 1292-1304, https://doi.org/10.1175/2010MWR3594.1, 2011.

Termonia, P., Voitus, F., Degrauwe, D., Caluwaerts, S., and Hamdi, R.: Application of Boyd's Periodization and Relaxation Method in a Spectral Atmospheric Limited-Area Model. Part I: Implementation and Reproducibility Tests, Mon. Weather Rev., 140, 3137-3148, https://doi.org/10.1175/MWR-D-12-00033.1, 2012.

Tudor, M.: Methods for automatized detection of rapid changes in lateral boundary condition fields for NWP limited area models, Geosci. Model Dev., 8, 2627-2643, https://doi.org/10.5194/gmd8-2627-2015, 2015.

Tudor, M. and Ivatek-Šahdan, S.: The case study of bura of 1 and 3 February 2007, Meteorol. Z., 19, 453-466, 2010.

Tudor, M. and Termonia, P.: Alternative Formulations for Incorporating Lateral Boundary Data into LimitedArea Models, Mon. Weather Rev., 138, 2867-2882, https://doi.org/10.1175/2010MWR3179.1, 2010.

Untch, A. and Hortal, M.: A finite-element scheme for the vertical discretization of the semi-Lagrangian version of the ECMWF forecast model, Q. J. Roy. Meteor. Soc., 130, 1505-1530, https://doi.org/10.1256/qj.03.173, 2004.

Uppala, S. M., Kållberg, P. W., Simmons, A. J., Andrae, U., Bechtold, V. D. C., Fiorino, M., Gibson, J. K., Haseler, J., Hernandez, A., Kelly, G. A., Li, X., Onogi, K., Saarinen, S., Sokka, N., Allan, R. P., Andersson, E., Arpe, K., Balmaseda, M. A., Beljaars, A. C. M., Berg, L. V. D., Bidlot, J., Bormann, N., Caires, S.,
Chevallier, F., Dethof, A., Dragosavac, M., Fisher, M., Fuentes, M., Hagemann, S., Hólm, E., Hoskins, B. J., Isaksen, L., Janssen, P. A. E. M., Jenne, R., Mcnally, A. P., Mahfouf, J.-F., Morcrette, J.-J., Rayner, N. A., Saunders, R. W., Simon, P., Sterl, A., Trenberth, K. E., Untch, A., Vasiljevic, D., Viterbo, P., and Woollen, J.: The ERA-40 re-analysis, Q. J. Roy. Meteor. Soc., 131, 29613012, https://doi.org/10.1256/qj.04.176, 2005.

Váña, F., Bénard, P., Geleyn, J.-F., Simon, A., and Seity, Y.: Semi-Lagrangian advection scheme with controlled damping: An alternative to nonlinear horizontal diffusion in a numerical weather prediction model, Q. J. Roy. Meteor. Soc., 134, 523537, https://doi.org/10.1002/qj.220, 2008.

Vié, B., Pinty, J.-P., Berthet, S., and Leriche, M.: LIMA (v1.0): A quasi two-moment microphysical scheme driven by a multimodal population of cloud condensation and ice freezing nuclei, Geosci. Model Dev., 9, 567-586, https://doi.org/10.5194/gmd-9567-2016, 2016.

Vivoda, J. and Smolíková, P.: Finite elements used in the vertical discretization of the fully compressible forecast model ALADIN-NH, ALADIN/HIRLAM Newsletter, No. 1, MétéoFrance, Toulouse, France, 31-46, 2013.

Wang, Y., Bellus, M., Wittmann, C., Steinheimer, M., Weidle, F., Kann, A., Ivatek-Šahdan, S., Tian, W., Ma, X., Tascu, S., and Bazile, E.: The Central European limited-area ensemble forecasting system: ALADIN-LAEF, Q. J. Roy. Meteor. Soc., 137, 483-502, 2011.

Wang, Y., Bellus, M., Geleyn, J.-F., Tian, W., Ma, X., and Weidle, F.: A new method for generating initial perturbations in regional ensemble prediction system blending, Mon. Weather Rev., 142, 2043-2059, 2014.

Warner, T. T., Peterson, R. A., and Treadon, R. E.: A Tutorial on Lateral Boundary Conditions as a Basic and Potentially Serious Limitation to Regional Numerical Weather Prediction, B. Am. Meteorol. Soc., 78, 2599-2617, 1997.

Wattrelot, E., Caumont, O., and Mahfouf, J.-F.: Operational Implementation of the 1D + 3D-Var Assimilation Method of Radar Reflectivity Data in the AROME Model, Mon. Weather Rev., 142, 1852-1873, https://doi.org/10.1175/MWR-D-13-00230.1, 2014.

Xu, K.-M. and Randall, D. A.: A semi-empirical cloudiness parameterization for use in climate models, J. Atmos. Sci., 53, 3084 3102, 1996.

Yano, J.-I., Bengtsson, L., Geleyn, J.-F., and Brozkova, R.: Parameterization of Atmospheric Convection, vol. 2: Current Issues and New Theories, Part IV Unification and consistency, chap. 26: Towards a unified and self-consistent parameterization Framework, Series on the Science of Climate Change, Imperial College Press, London, UK, 2016.

Zilitinkevich, S. S., Elperin, T., Kleeorin, N., Rogachevskii, I., and Esau, I.: A hierarchy of energy- and flux-budget (EFB) turbulence closure models for stably-stratified geophysical flows, Bound.-Lay. Meteorol., 146, 341-373, https://doi.org/10.1007/s10546-012-9768-8, 2013.

Zwieflhofer, W., Kreitz, N., and Forecasts, E.: Realizing Teracomputing: Proceedings of the Tenth ECMWF Workshop on the Use of High Performance Computing in Meteorology, 4-8 November 2002, Reading, UK, World Scientific, 2003. 